\title{
Oncolytic Viruses and Immune Checkpoint Inhibitors: Preclinical Developments to Clinical Trials
}

\author{
June Kyu Hwang ${ }^{1, \dagger}$, JinWoo Hong ${ }^{1,2, \dagger}$ and Chae-Ok Yun $1,2,3, * \mathbb{C}$ \\ 1 Department of Bioengineering, College of Engineering, Hanyang University, 222 Wangsimni-ro, \\ Seongdong-gu, Seoul 04763, Korea; psients@gmail.com (J.K.H.); jhong803@gmail.com (J.H.) \\ 2 GeneMedicine Co., Ltd., 222 Wangsimni-ro, Seongdong-gu, Seoul 04763, Korea \\ 3 Institute of Nano Science and Technology, 222 Wangsimni-ro, Seongdong-gu, Seoul 04763, Korea \\ * Correspondence: chaeok@hanyang.ac.kr \\ $\dagger$ These authors contributed equally to this work.
}

Received: 13 October 2020; Accepted: 6 November 2020; Published: 16 November 2020

\begin{abstract}
Immuno-oncology (IO) has been an active area of oncology research. Following US FDA approval of the first immune checkpoint inhibitor (ICI), ipilimumab (human IgG1 k anti-CTLA-4 monoclonal antibody), in 2011, and of the first oncolytic virus, Imlygic (talimogene laherparepvec), in 2015, there has been renewed interest in IO. In the past decade, ICIs have changed the treatment paradigm for many cancers by enabling better therapeutic control, resuming immune surveillance, suppressing tumor immunosuppression, and restoring antitumor immune function. However, ICI therapies are effective only in a small subset of patients and show limited therapeutic potential due to their inability to demonstrate efficacy in 'cold' or unresponsive tumor microenvironments (TMEs). Relatedly, oncolytic viruses (OVs) have been shown to induce antitumor immune responses, augment the efficacy of existing cancer treatments, and reform unresponsive TME to turn 'cold' tumors 'hot,' increasing their susceptibility to checkpoint blockade immunotherapies. For this reason, OVs serve as ideal complements to ICIs, and multiple preclinical studies and clinical trials are demonstrating their combined therapeutic efficacy. This review will discuss the merits and limitations of OVs and ICIs as monotherapy then progress onto the preclinical rationale and the results of clinical trials of key combination therapies.
\end{abstract}

Keywords: oncolytic virus 1; immune checkpoint inhibitor 2; immuno-oncology 3; combination therapy 4

\section{Introduction}

In past decades, cancer treatment has made tremendous progress to include a range of therapies. One specific therapeutic area, immuno-oncology (IO), has received much renewed attention for its ability to take advantage of the body's immune system to fight cancer. Specifically, the development of antibodies $(\mathrm{Ab})$ that target key immune checkpoint molecules served as a revolutionary milestone in the field of IO, as the Abs were able to disrupt the cancer cells' ability to evade the host immune response and activate anti-tumor immunity [1,2]. Such developments led to the first US FDA-approved immune checkpoint inhibitor (ICI), ipilimumab-a cytotoxic T-lymphocyte antigen-4 (CTLA-4)-targeting monoclonal $\mathrm{Ab}$ - for the treatment of patients with advanced melanoma [1]. After approval of ipilimumab, several other immune checkpoint blockade agents were examined, leading to numerous clinical trials that examined the efficacy of ICIs for either mono or combination therapy. To date, six other ICIs have been approved by the US FDA, comprising programmed death 1 (PD-1) inhibitors (pembrolizumab, nivolumab, and cemiplimab) and programmed death-ligand 1 (PD-L1) inhibitors (avelumab, durvalumab, and atezolizumab) [1]. Overall, the increase in ICIs is part of the growing IO 
trend: between 2017 and 2019, Tang et al. found a 91\% increase in the number of active agents, a 78\% increase in active IO targets, and a $60 \%$ increase in participating IO drug development organizations, resulting in 31 IO drug approvals by the US FDA [3].

Despite the impact of ICIs in IO and their potential in the clinical setting, accumulating evidence suggests that researchers must overcome some critical limitations: (a) some patients undergoing ICI therapy experience severe immune-related adverse events (irAE) [4], (b) only a fraction of cancer patients benefit from ICI treatment, and c) ICIs are ineffective against immunologically 'cold' tumors characterized by a low tumor infiltrating lymphocyte (TIL) count [5]. To this end, oncolytic viruses $(\mathrm{OV})$, which preferentially infect and lyse cancer cells, have been proposed as a promising modality for combination therapy to address the limitations of ICI. This is due to the unique ability of OVs to inflame a "cold" tumor microenvironment (TME) into a "hot" environment with increased immune cell and lymphocyte infiltration, making them an ideal candidate for combination with various cancer immunotherapeutics [5]. For this reason, multiple ongoing clinical trials are aiming to investigate the combined therapeutic efficacy of ICIs and OVs. This review will discuss the underlying rationale behind ICIs and OVs as a synergistic combination therapy regimen and their application in preclinical and clinical settings (Table 1: List of Ongoing Combination Clinical Trials with Oncolytic Viruses and Immune Checkpoint Inhibitors).

Table 1. List of ongoing combination therapy clinical trials with oncolytic viruses and immune checkpoint inhibitors.

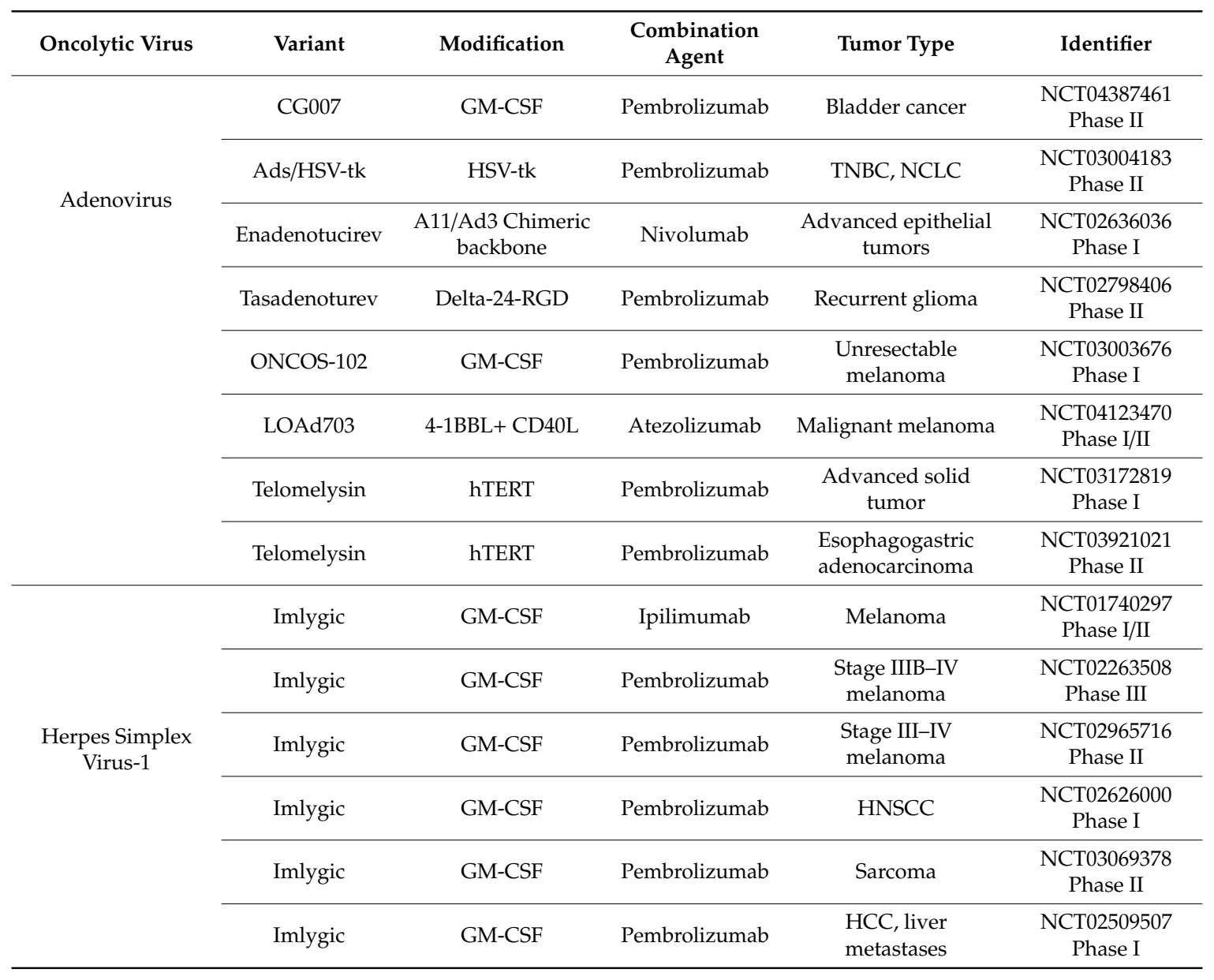


Table 1. Cont.

\begin{tabular}{|c|c|c|c|c|c|}
\hline Oncolytic Virus & Variant & Modification & $\begin{array}{l}\text { Combination } \\
\text { Agent }\end{array}$ & Tumor Type & Identifier \\
\hline & Imlygic & GM-CSF & $\begin{array}{l}\text { Nivolumab + } \\
\text { Trabectedin }\end{array}$ & Sarcoma & $\begin{array}{c}\text { NCT03886311 } \\
\text { Phase II }\end{array}$ \\
\hline & Imlygic & GM-CSF & Atezolizumab & TNBC, CRC & $\begin{array}{c}\text { NCT03256344 } \\
\text { Phase I }\end{array}$ \\
\hline & HF10 & $\begin{array}{l}\text { Spontaneously } \\
\text { mutated }\end{array}$ & Ipilimumab & Melanoma & $\begin{array}{c}\text { NCT02272855 } \\
\text { Phase II }\end{array}$ \\
\hline & HF10 & $\begin{array}{l}\text { Spontaneously } \\
\text { mutated }\end{array}$ & Nivolumab & $\begin{array}{l}\text { Stage IIIB, IIIC and } \\
\text { IVM1a melanoma }\end{array}$ & $\begin{array}{c}\text { NCT03259425 } \\
\text { Phase II }\end{array}$ \\
\hline Vaccinia Virus & Pexa-Vec & $\begin{array}{c}\text { Human GM-CSF + } \\
\beta \text {-galactosidase }\end{array}$ & Nivolumab & $\mathrm{HCC}$ & $\begin{array}{l}\text { NCT03071094 } \\
\text { Phase I/II }\end{array}$ \\
\hline \multirow{3}{*}{ Coxsackievirus } & CAVATEK & Unmodified & Ipilimumab & Uveal melanoma & $\begin{array}{l}\text { NCT03408587 } \\
\text { Phase I }\end{array}$ \\
\hline & CAVATEK & Unmodified & Ipilimumab & Melanoma & $\begin{array}{c}\text { NCT02307149 } \\
\text { Phase I }\end{array}$ \\
\hline & CAVATEK & Unmodified & Pembrolizumab & Melanoma & $\begin{array}{c}\text { NCT02565992 } \\
\text { Phase I }\end{array}$ \\
\hline $\begin{array}{c}\text { Vesicular } \\
\text { Stomatitis Virus }\end{array}$ & VSV- IFN $\beta-N I S$ & $\begin{array}{l}\text { IFN } \beta \text { and sodium } \\
\text { importer gene }\end{array}$ & Avelumab & $\begin{array}{l}\text { Refractory solid } \\
\text { tumor }\end{array}$ & $\begin{array}{l}\text { NCT02923466 } \\
\text { Phase I }\end{array}$ \\
\hline \multirow{5}{*}{ Maraba Virus } & $\begin{array}{l}\text { MG1-MAGEA3 } \\
+ \text { Ad MAGEA3 }\end{array}$ & MAGE & Pembrolizumab & NSCLC & $\begin{array}{l}\text { NCT02879760 } \\
\text { Phase I/II }\end{array}$ \\
\hline & MG1-E6E7 & HPV E6 and E7 & Atezolizumab & $\begin{array}{l}\text { HPV-associated } \\
\text { cancers }\end{array}$ & $\begin{array}{c}\text { NCT03618953 } \\
\text { Phase I }\end{array}$ \\
\hline & $\begin{array}{l}\text { MG1-MAGEA3 } \\
+ \text { Ad MAGEA3 }\end{array}$ & MAGE & Pembrolizumab & Metastatic melanoma & $\begin{array}{l}\text { NCT03773744 } \\
\text { Phase I }\end{array}$ \\
\hline & PVSRIPO & $\begin{array}{l}\text { Human rhinovirus } \\
\text { type } 2 \text { (HRV2) IRES }\end{array}$ & Nivolumab & Melanoma & $\begin{array}{c}\text { NCT04125719 } \\
\text { Phase I }\end{array}$ \\
\hline & PVSRIPO & $\begin{array}{l}\text { Human rhinovirus } \\
\text { type } 2 \text { (HRV2) IRES }\end{array}$ & Atezolizumab & RGBM & $\begin{array}{c}\text { NCT03973879 } \\
\text { Phase I/II }\end{array}$ \\
\hline $\begin{array}{c}\text { Newcastle Disease } \\
\text { Virus }\end{array}$ & MEDI5395 & GM-CSF & Durvalumab & $\begin{array}{l}\text { Advanced solid } \\
\text { tumors }\end{array}$ & $\begin{array}{l}\text { NCT03889275 } \\
\text { Phase I }\end{array}$ \\
\hline
\end{tabular}

\section{Immune Checkpoint Inhibitors}

Immune checkpoints are regulators of the immune system that are crucial for self-tolerance and prevention of the immune system from attacking cells indiscriminately [6]. Many tumors evade the host immune system by upregulating immune checkpoints to generate immunosuppressive TME [7]. ICIs work by disrupting such tumor immunosuppressive signaling pathways, exposing the cancer cells to the host immune system. There has been overwhelming preclinical evidence validating PD-1, PD-L1 and CTLA-4 inhibitors as viable targets for IO therapy, with demonstrated clinical efficacy against several solid and hematologic malignancies [1]. To date, six US FDA-approved drugs, comprised of three PD-1 inhibitors (nivolumab, pembrolizumab, and cemiplimab), three PD-L1 inhibitors (atezolizumab, avelumab, and durvalumab) and two CTLA-4 inhibitors, are used in the 
clinical setting $[1,8]$. In addition, new emerging checkpoint inhibitors targeting lymphocyte-activation gene 3 (LAG-3) [9,10] or T cell immunoglobulin and mucin-domain containing-3 (TIM-3) [11] have demonstrated promising preclinical results and in clinical development.

Although ICIs have had an unprecedented effect on the clinical activity of several cancers to transform IO, ICIs-both as mono and combination therapy-are not without limitations. Primarily, ICIs are known to have a broad range of side effects affecting every organ system, as well as producing irAE in a significant incidence of patients [12]. Flaherty et al. identified longer follow-ups of clinical trial population studies to accumulate evidence of late relapses, suggesting an emergence of acquired resistance to ICIs [13]. There are several interesting targets, like pattern recognition receptors, that were successfully exploited in preclinical models to circumvent resistance to T cell-targeted ICIs, but these investigations are in early stages and none have reached the clinical development stage [14]. In addition, several groups have reported that a diversity of neoantigens may be necessary to induce a sufficient clinical response from ICIs [15], with van Rooij et al. [16] and Le et al. [17] observing neoantigen-specific $\mathrm{T}$ cell reactivity in patients with advanced cancers. Moreover, several groups have substantiated the role of neoantigens in response to ICIs, supported by evidence of higher neoantigen load being associated with better therapeutic response to CTLA-4 and PD-1 blockade in patients with melanoma and non-small-lung cancer [18-20]. However, ICIs are most critically limited by their refractoriness or ineffectiveness in 'cold' TME, as there is a lack of T cell infiltration, resulting in overall suppression of host antitumor immune response [5]. Furthermore, as many types of cancers present with 'cold' tumors, ICIs are critically limited in therapeutic potential, necessitating the identification of novel IO candidates as combination therapies to maximize the clinical benefits of individual ICIs.

\section{Development of Oncolytic Viruses in Combination with Immune Checkpoint Inhibitors}

Oncolytic viruses (OVs) are native or recombinant viruses that self-propagate, selectively replicate in cancer cells, and infect adjacent cancer cells to elicit a cytolytic effect. Specifically, OVs differ from conventional cancer therapies in that they have naturally evolved to effectively hijack and reprogram the host's cellular machinery, effectively expressing both virus and therapeutic transgenes at a high level [21]. OVs have been demonstrated to stimulate the immune system by infecting a tumor cell to induce immunogenic cell death, which triggers an inflammatory reaction. This particular form of apoptosis results in the release of immune stimulatory agents, which activate innate and direct adaptive immune responses against cancer cells by the release of pathogen-associated molecular patterns (PAMPS), tumor-associated antigens (TAAs), and danger-associated molecular patterns (DAMPS) from lysed tumor cells $[22,23]$. APCs in the TME then recognize these key metabolites and generate an immune response. Furthermore, this local stimulation of the immune system creates a systemic and enduring anti-cancer response [24]. Importantly, these attributes of OVs have been shown to revert immunologically 'cold' or 'non-inflamed' tumors with low TIL count into 'hot' tumors, indicating them as promising candidates to synergize with cancer immunotherapeutics [24-26]. There is a strong line of evidence that suggests viruses, like rotavirus, influenza or yellow fever virus, can also prime TME of cold tumors to be more responsive toward immunotherapy [27]. In particular, efforts to synergize OVs with other IO drugs have demonstrated OV infections to increase the expression levels of several proinflammatory cytokines and cause an influx of natural killer cells (NKs), activated T cells, and APCs into tumor tissues [28], priming unresponsive TMEs into more conducive targets for other cancer immunotherapeutics.

OVs provide additional versatility as effective anticancer agents, as they can be genetically engineered to possess specificity toward tumor cells and to preferentially lyse malignant cells, focusing their therapeutic transgene delivery and simultaneously reducing potential off-target side effects [29]. Importantly, arming OVs with antitumor immune transgenes, like cytokines, can lead to localized and high expression levels of these genes in tumor tissues, with minimal systemic circulation. These attributes allow OVs to deliver potent immune stimulators, like IL-12 [30] and 4-1BBL [31], among others, which had failed in clinical development as protein therapeutics due to their high systemic toxicity [32]. 
Despite these remarkable advances in OV IO, these viruses must overcome certain challenges to achieve clinical application and commercialization. Namely, most early clinical trials that administered OVs intratumorally as a monotherapy were not able to demonstrate a sufficient therapeutic outcome [33-35]. OVs have been shown to be susceptible to selective pressure of heterogeneous tumor populations when administered over an extended period of time, as these viruses lose essential signaling pathways by mutation or lose important receptors that mediate their life cycle [36].

Due to the above limitations, first-generation OVs like Rigvir and ONYX-015 have shown limited therapeutic efficacy as monotherapies, and their approval for in-human use has been restricted to the countries (Latvia and China, respectively) that commercialized these products $[37,38]$. Rigvir, a non-pathogenic ECHO-7 virus with no genetic modifications, was the first OV approved by regulatory authorities, gaining approval in Latvia in 2004 for the treatment of melanoma [37]. However, Rigvir did not achieve global commercialization; most of its clinical studies were performed before 1991, its safety and efficacy parameters needed to be updated to modern standards, and its response rate needed to be increased by optimizing its biomarkers toward more specific target populations [37]. Since Rigvir, several other OVs, which are innately oncolytic without genetic modification of the virus genome, have entered clinical development in the US and EU [39]. Still, most first-generation OVs, such as Oncorine (previously designated as ONYX-015) and HSV1716, which began clinical trials in the 1990s, as well as those that are currently under clinical evaluation, harbor several genetic modifications to improve the cancer specificity of virus strains. The first such genetically modified OV to be approved by a regulatory authority was Oncorine, which was approved by the Chinese FDA in 2005 for the treatment of solid tumors [40]. Despite gaining Chinese FDA approval, Oncorine's development in the US and EU failed to induce significant tumor growth inhibition in patients when used as a monotherapy and only achieved meaningful clinical therapeutic responses when used in combination with chemotherapy [41] or radiotherapy [42], demonstrating its inadequacies and suboptimal potency as a monotherapy.

Since commercialization of Rigvir and Oncorine in the early 2000s, only one other OV, Imlygic, has been approved for human use. Imlygic (granulocyte-macrophage colony-stimulating factor (GM-CSF)-armed, herpes simplex virus type 1 (HSV10)), which was approved by the US and EU FDAs in 2015 and by the AUS FDA in 2016 [43,44], remains the only internationally available OV with a proven clinical track record as a monotherapy against melanoma [45]. Unlike Rigvir and Oncorine, developed in the 1990s, which were primarily evaluated in a clinical setting for direct oncolytic effects, Imlygic was designed to maximize its therapeutic potential as a next-generation IO therapeutic, armed with antitumor immune-boosting transgenes like GM-CSF, and clinically examined with a strong emphasis on immune-related evaluation parameters, such as immune cell infiltration into tumor tissues and cytokine profiling. In general, this IO-oriented clinical development process of Imlygic outlines the drastic change in the perception of OVs as cancer immunotherapeutics in the modern cancer therapy landscape. There is a growing amount of evidence supporting this IO-driven development process: for instance, several studies have shown that OVs exerting minimal cytolytic effect against tumors can effectively suppress the growth of injected and non-injected distal tumors by inducing an antitumor immune response [46]. The landmark approval of Imlygic has accelerated clinical development of other OVs. Imlygic has been evaluated in the largest number of ongoing and completed clinical trials for any particular OV, as either a monotherapy or a combination therapy, and has generated large quantities of clinical data $[47,48]$. Such trials have demonstrated that OVs can inflame the immunosuppressed TMEs of clinical tumors and have provided strong empirical evidence for combining ICIs with OVs $[23,49,50]$. A positive phase II clinical trial results from "Ipilimumab With or Without Imlygic in Unresected Melanoma (NCT01740297)" was the first to demonstrate that synergistic therapeutic efficacy can be achieved with combination of OV and ICI in cancer patients, as a higher level of cytotoxic T cell infiltration in tumors was observed following combination treatment [47] compared to that following ipilimumab monotherapy [47]. Notably, the combination of Imlygic and ipilimumab did not induce more severe side effects than monotherapy, whereas ipilimumab in combination with other ICIs has been reported to elevate the incidence rates and severities of adverse events [51]. Not only does this 
evidence support OVs as a viable and effective complementary therapy strategy in combination with ICIs, but it also sets a precedent for future combination therapies for clinical development, which are discussed in detail below.

\section{Oncolytic Viruses in Combination with Immune Checkpoint Inhibitors in Clinical Trials}

\subsection{Adenovirus}

Adenoviruses (Ads) are non-enveloped and double-stranded DNA viruses [52] with an icosahedral capsid. These viruses range from 70-90 nm in size and possess a genome of approximately $35 \mathrm{~kb}$ [53]. While 57 known Ad serotypes exist, serotype 5 is the most commonly used backbone in OVs [54]. Ads are one of the most commonly used viral vectors in cancer gene therapy due to their advantageous characteristics, which include high gene transfer efficiency in both dividing and non-dividing cells, low risk of insertional mutagenesis, and exponential viral replication capacity (one infectious virus can produce more than 10,000 progeny viruses in an infected cancer cell) [21,45,55-57]. Furthermore, Ads have been shown to elevate the expression level of immunostimulatory signals to enhance TAA presentation by APC to induce a strong, tumor-specific immune response [12], illustrating them as one of the most immunogenic OVs [58]. For this reason, several oncolytic Ads are under evaluation in clinical trials as monotherapies and in combination with ICIs.

\subsubsection{Tasadenoturev (DNX-2401) + Pembrolizumab}

DNX2401 is an oncolytic Ad with improved infectivity and tumor selectivity [59], achieved by a 24-bp deletion in the $\mathrm{Rb}$ binding site of the E1A region, which enables selective replication in cancer cells that lack a functional $\mathrm{Rb}$ pathway [60]. With positive preclinical evaluation studies [61], DNX2401 is currently undergoing three clinical trials as a monotherapy (NCT03714334, NCT03896568, and NCT03178032) for treatment of malignant gliomas. While the vector showed tumor size reductions in $72 \%$ of patients following intratumoral injection, with a median overall survival time of 9.5 months [62]. More relevant to the scope of this review is that Lang et al. found decreased TIM-3 expression through immunohistochemical analysis of resected tumor specimens [63]. TIM-3 is an immune inhibitory receptor that is known to promote T cell exhaustion [62], and the author suggests that DNX-2401 infection may overcome some aspects of the $\mathrm{T}$ cell exhaustion of glioma patients, providing a rationale to investigate the vector in combination with anti-PD-1 Ab [63]. A phase II trial is currently ongoing to investigate intratumorally administered DNX-2401, followed by the PD-1 inhibitor pembrolizumab in RGBM patients (NCT02798406). Interim results have been reported for 48 subjects who received the combination of pembrolizumab and DNX-2401 and achieved a median overall survival of 12 months; $47 \%$ experienced a clinical benefit (stable disease or better). In detail, four subjects had partial responses, two of whom showed $94 \%$ regression of tumor volume and three survived for more than 20 months [64].

\subsubsection{ONCOS-102 (Ad 5/3 $\Delta 24$ GM-CSF) + Pembrolizumab}

ONCOS-102 is a highly modified oncolytic Ad vector including a chimeric 5/3 fiber-knob region for increased infectivity, a 24-bp deletion in the E1A region for selective replication in cells with dysfunctional $\mathrm{Rb}$ pathway, and the transgene insertion of GM-CSF to improve immune cell infiltration at the tumor site [65,66]. ONCOS-102 has been extensively tested in preclinical investigations [65] and has progressed to a phase I clinical trial (NCT03003676) in combination with the PD-1 ICI pembrolizumab. This phase I trial, which treated 12 patients with advanced or unresectable solid tumors, concluded ONCOS-102 to be safe and well tolerated at the tested doses, and combination therapy induced significant immune cell infiltration at the tumor sites [66]. The results of the study concluded that the combination therapy produced 5.9- and 4.0-fold increases in infiltration of CD3+ immune cells and CD8+ T cells, respectively, in post-treatment tumor biopsies compared to pre-treatment samples [66]. Interestingly, 2 of the 12 patients demonstrated increased PD-L1 expression following ONCOS-102 administration and developed systemic anti-tumor immunity, made evident by 
melanoma associated antigen 3 (MAGE-A3)-specific $\mathrm{CD}^{+} \mathrm{T}$ cells and New York esophageal squamous cell carcinoma 1(NY-ESO-1)-specific CD8 ${ }^{+} \mathrm{T}$ cells $[67,68]$. Following these observations, ONCOS-102 has motivated another phase I clinical trial (NCT03003676), which aims to utilize ONCOS-102 with pembrolizumab in recurrent patients after PD1 blockade.

\subsubsection{Enadenotucirev + Nivolumab}

Enadenotucirev is an Ad11p/Ad3 chimeric oncolytic Ad that was shown to elicit potent antitumor efficacy in orthotopic human tumor xenograft models $[69,70]$. To date, two phase I clinical studies have been conducted to assess the safety of the virus, expanding upon preclinical evidence supporting enadenotucirev's uniqueness among OVs, namely, its superior stability in the bloodstream following intravenous delivery [63,71,72], and the low prevalence of neutralizing Ab against enadenotucirev in the general population $[73,74]$. The results from the first trial revealed that intravenous infusion of enadenotucirev in patients with epithelial tumors can induce infiltration of a large number of $\mathrm{CD} 8^{+} \mathrm{T}$ cells into most tumor samples [63] and provided a rationale to investigate the virus in combination with an anti-PD-1 Ab, nivolumab, in patients with epithelial carcinoma (NCT02636036). Currently, NCT02636036 is actively recruiting trial participants.

\subsubsection{Other Adenoviruses}

More Ads are expected to enter clinical trials as complementary therapies with ICIs due to their strong immunostimulatory properties $[75,76]$. TILT-123, an oAd armed with two potent anti-tumor cytokines (tumor necrosis factor [TNF]-alpha and IL-2) that promote immune cell recruitment to TMEs, is one of the candidates that is expected to enter a phase I clinical trial by 2021, in combination with the anti-PD-L1 ICI avelumab [77]. This is based on strong preclinical evidence of TILT-123 in combination with an anti-PD-L1 ICI exerting a strong antitumor immune response in patient-derived urological tumor histocultures, as evidenced by the high expression levels of antitumor cytokines and $\mathrm{T}$ cell trafficking chemokine CXCL10 that positively correlated with increased intratumoral infiltration of CD8+ T cells [78]. The combination therapy led to complete regression of tumors and superior survival rate in comparison to either ICI or OV monotherapy in an animal model, showing that the immune stimulatory property of oncolytic Ad could achieve promising therapeutic outcomes in combination with PD-L1-targeted ICIs [79].

Two other oncolytic Ads have recently entered clinical trials as combination therapies with ICIs, and this continuous increase in the number of clinical investigations highlights the promising nature of this strategy. In detail, CG0070, a GM-CSF-armed serotype 5 oAd [80,81], entered phase II clinical trial in combination with pembrolizumab (NCT04387461) in May 2020. The study is expected to evaluate the activity of CG0070 through intravesical administration along with intravenous administration of pembrolizumab in patients with non-muscular invasive bladder cancer. Another virus, OBP-301, a serotype $5 \mathrm{oAd}$ replicating under the control of a human telomerase reverse transcriptase promoter [82], began a phase I trial in combination with a PD-1 inhibitor, pembrolizumab (NCT03172819), for the treatment of advanced solid tumors.

As an alternative to combination therapy, where an ICI and OV are sequentially administered, several groups have investigated the insertion of ICIs, such as 4-1BBL [83] and miniaturized Ab against anti-PD1 or anti-CTLA-4, into oAd as therapeutic transgenes [84]. To date, Hemminki et al. have developed the first Ad to produce a full-length CTLA-4 monoclonal Ab (Ad 5/3 $\triangle 24$ a CTLA4) while retaining the oncolytic potency of the virus, overcoming the limitations of the CTLA-4 blockade with monoclonal $\mathrm{Ab}$, which has been shown to inhibit viral replication [85]. In addition, the author demonstrated effective induction of $\mathrm{T}$ cell activity in in vitro and in vivo models in normal donors and in patients with advanced solid tumors [86]. Meanwhile, Du et al. have reported the generation of an oAd (SKL002) with an anti-CTLA4 Ab gene inserted into the E3 region of the viral genome with anti-tumor efficacy in both in vitro and in vivo models [85]. 


\subsection{Herpes Simplex Virus-1}

HSV is a virus characterized by an icosahedral capsid, approximately $200 \mathrm{~nm}$ in size, and a linear, 150-kb double-stranded DNA genome [87,88]. Oncolytic HSV (oHSV) has been extensively used in clinical immunotherapy and is considered a useful oncolytic vector due to its large transgene capacity, lack of insertional mutagenesis, and ability to activate innate and adaptive immune responses against tumors [89]. Furthermore, HSV infection can be controlled by well-established antiviral drug regimens, ensuring greater safety in the case of a vector that threatens the life of the patient $[90,91]$. To date, various strains of HSV are used as monotherapies and have successfully expressed various transgenes, such as p53 [92], IL-2 [93,94], and IFN- $\gamma$ [95], in preclinical studies. Currently, Imlygic remains the only US FDA-approved OV, but several other oHSVs have progressed to phase II/III clinical trials.

\subsubsection{Imlygic + Ipilimumab and Imlygic + Pembrolizumab}

Imlygic is the first and only US FDA-approved OV and includes GM-CSF and deletion in the ICP34.5 gene to augment the tumor specificity of the virus [96,97]. Imlygic is the most extensively characterized OV in clinical settings. During the landmark OPTiM phase III trial, which subsequently led to commercialization of Imlygic, intralesional injection of the virus in patients with metastatic melanoma was shown to change the immune cell makeup of the TME into a immunologically 'hot' environment, as evidenced by decreases in immunosuppressive cell populations (Tregs, CD8+ T suppressor cells, and myeloid-derived suppressor cells) [98]. In addition, Imlygic increased the local and systemic T cell-recognized melanoma antigen (MART)-1-specific CD8+ effector cell populations, demonstrating the establishment of tumor-specific adaptive immunity by OV treatment [99].

These immune stimulatory properties of Imlygic and the inflammation of TME observed during the monotherapy trials provided a strong rationale for subsequent clinical investigation of the virus in combination with ICIs. A phase Ib trial investigating Imlygic in combination with a CTLA-4 inhibitor, ipilimumab, was conducted in patients with untreated late stage melanoma and achieved positive results [100]. In detail, the combination therapy led to an objective response rate and a durable response rate of 50\% and 44\%, respectively [101], and there were no dose-limiting toxicities (DLTs) or compounding overall adverse events compared to those of ipilimumab monotherapy [101]. In a subsequent phase II trial, 39\% of patients in the combination group (Imlygic + ipilimumab) had an objective response, while only $18 \%$ of patients in the ipilimumab monotherapy arm responded. Furthermore, an abscopal response, a decrease in non-injected visceral lesions, was observed in 52\% of patients in the combination group compared to $23 \%$ in the ipilimumab group [47]. These results confirmed that the combination therapy can elicit synergistic and systemic antitumor effects against both virus-injected tumors and distant non-injected metastases.

Imlygic also has been investigated as a combination therapy with the anti-PD-1 Ab pembrolizumab for treatment of melanoma, with promising results. The interim results of the MASTERKEY-265/KEYNOTE-034 phase Ib/III trial (NCT02263508) revealed that the combination therapy resulted in an objective response rate of $62 \%$, with a complete response rate of $33 \%$, no DLT, increased intratumoral expression level of PD-L1, and increased amounts of circulating T cells, inflaming both the virus-injected and non-injected distal tumor sites [23]. While this clinical trial is ongoing, anticipated results from MASTERKEY-265/KEYNOTE-034 have set a precedent for other clinical investigations combining ICIs with Imlygic (Table 1).

\subsubsection{C-REV + Ipilimumab and C-REV + Nivolumab}

C-REV (formerly HF-10) is an oHSV derived from spontaneous mutation and does not express any therapeutic transgenes [102]. In preclinical studies, C-REV replicated effectively within tumors and induced an antitumor immune response, as evidenced by an increase in the numbers of activated $\mathrm{CD} 4^{+}$, $\mathrm{CD}^{+} \mathrm{T}$, and NK cells in tumor tissues, leading to prolonged survival and a significant reduction in tumor growth [102]. With strong preclinical evidence of a robust antitumor immune response, C-REV 
progressed to a phase II clinical trial as a combination therapy with the CTLA-4 inhibitor ipilimumab for treatment of the late stages of unresectable melanoma (NCT02272855).

Following the success of this clinical trial, two recent clinical trials have set out to investigate C-REV as a combination therapy with a CTLA-4 inhibitor, ipilimumab (NCT03153085), in Japanese patients with unresectable or metastatic melanoma or with a PD-1 inhibitor, nivolumab (NCT03259425), in patients with resectable stage IIIB, IIIC, or IVM1a melanoma. In the interim report of the NCT03259425 trial, patients receiving the combination of C-REV and ipilimumab demonstrated higher $\mathrm{T}$ cell infiltration into tumors than those achieved with the respective monotherapies in previous clinical trials [103], lower levels of PD-L1 on monocytes after 2 months of treatment, and persistent C-REV infection in 5 of 11 patients [104]. The combination of C-REV and ipilimumab was shown to exert potent anti-tumor activity, with an overall response rate and disease control rate of $41 \%$ and $68 \%$, respectively, which were higher than the $4 \%$ and $16 \%$ achieved by ipilumab monotherapy from a trial in Japanese patients with melanoma [105]. The addition of C-REV therapy did not exacerbate the toxicity of ipilumab, as similar rates of grade 3 or higher adverse events were observed in the combination therapy trial to those observed with the previous trial evaluating ipilumab monotherapy in melanoma patients.

\subsection{Vaccinia Virus}

Vaccinia virus is a member of the Poxviridae family and possesses a large double-stranded DNA of $190 \mathrm{~kb}$, indicating its suitability for large transgene insertion [106]. Furthermore, vaccinia virus replicates in the cytoplasm, eliminating the risk of insertional mutagenesis [53]. In addition, vaccinia viruses have a rapid replication and infection cycle that starts as early as $2 \mathrm{~h}$ after infection, with cell lysis taking place between 12 and $48 \mathrm{~h}$ [107]. For these reasons, vaccinia viruses are useful in the development of oncolytic virotherapy.

Pexa-Vec + Nivolumab and Pexa-Vec + Durvalumab or Pexa-Vec + Durvalumab + Tremelimumab and Pexa-Vec + Ipilimumab

Pexa-Vec is an oncolytic vaccinia virus with a thymidine kinase gene deletion that expresses GM-CSF and $\beta$-galactosidase as transgenes [107-109]. Pexa-Vec has been demonstrated to be capable of targeting and infecting tumor-associated endothelial cells [110]. In a preclinical setting, Pexa-Vec intravenous administration prior to surgical resection in patients with advanced solid tumors was shown to activate NK cells as well as $\mathrm{CD} 4^{+}$and $\mathrm{CD} 8^{+} \mathrm{T}$ cells in tumor tissues, in addition to elevating the expression levels of antitumor immune cytokines including IFN- $\alpha$, IL-3, IL-12p40, IL-16, and IL-18 [110]. A phase Ib trial of intravenously administered Pexa-Vec for the treatment of colorectal cancer revealed that systemically administered virus can be trafficked to the tumor, as evidenced by a viral genome in tumor biopsies from seven of eight evaluable patients [107]. Furthermore, systemic administration of Pexa-Vec in patients with solid tumors prior to surgical resection was reported to induce robust activation of NK, CD14+ APC, CD4+, and CD8+ T cells in peripheral blood mononuclear cells, showing evidence of antitumor immune response induction [111,112]. Based on these encouraging antitumor immunostimulatory properties of Pexa-Vec as a monotherapy, Pexa-Vec in combination with a PD-1 inhibitor, nivolumab, is being evaluated as a first-line therapy in a phase I/II clinical trial in patients with renal carcinoma (NCT03071094) [89], which has no published results available to date.

Pexa-Vec is being investigated in another phase I/II trial with the PD-1 inhibitor durvalumab, as well the CTLA-4 inhibitor tremelimumab, in 35 patients with refractory colorectal cancer (NCT03206073). Specifically, two doses of Pexa-Vec were injected intravenously four times together with repeated infusions of durvalumab (group A) or a combination of durvalumab and tremelimumab (group B) [113]. Although no interim results of the clinical trials are available, a preclinical evaluation of the same combination therapy regimens in murine renal carcinoma tumor models revealed that locally administered Pexa-Vec in combination with either PD-1- or CTLA-4-targeted ICI resulted in superior 
tumor growth inhibition compared to monotherapy with either the virus or the respective ICIs in both the virus-injected primary tumor and the non-injected distal tumors. This response was due to increased $\mathrm{CD} 4+$ and $\mathrm{CD} 8^{+} \mathrm{T}$ cell infiltration into the tumor tissues [114]. Intriguingly, systemic administration of Pexa-Vec in combination with a PD-1 inhibitor led to a smaller quantity of virus in tumor tissues with respect to Pexa-Vec monotherapy, whereas the virus quantity in tumors following local administration of Pexa-Vec was unaffected by PD-1 ICI combination therapy. These findings suggest that $\mathrm{T}$ cell activation by PD-1 ICI may hamper the therapeutic efficacy of systemic oncolytic virotherapy, and this could be one of the underlying reasons why most OV and ICI combination therapy regimens in clinical development employ local administration of OV. Importantly, the triple combination of Pexa-Vec with PD-1 and CTLA-4 ICIs induced superior tumor growth inhibition in comparison to dual ICI combination therapy (PD-1 and CTLA-4 ICI) or Pexa-Vec monotherapy, resulting in complete tumor regression in $40 \%$ of treated mice; in contrast, Pexa-Vec in combination with a single ICI failed to induce complete regression.

As ICI combination therapy regimens are under active clinical investigation, Pexa-Vec's ability to synergize with different ICIs is a promising attribute. Unfortunately, the study did not include safety assessment of the triple combination strategy. Intratumorally administered Pexa-Vec in combination with the CTLA-4 inhibitor ipilimumab in patients with metastatic or advanced tumors is being evaluated in a phase I clinical trial (NCT02977156). The study is aiming to conduct a two-part phase I trial to define the feasibility, safety, and antitumor effects of the combination therapy and is currently recruiting participants.

\subsection{Coxsackievirus}

Coxsackievirus is a small, 30-nm-sized, non-enveloped, single-stranded RNA virus with an icosahedral capsid belonging to the Picornaviridae family [53]. While the virus is grouped into two subtypes, $\mathrm{A}$ and $\mathrm{B}$, the serotype $\mathrm{A} 21$ has been most commonly utilized in clinical trials for its inherent cytotoxicity against cancer cells [115]. Serotypes A13, A15, and A18 are being explored for oncolytic potential [116]. Coxsackievirus A21 is a naturally occurring OV and has not been as extensively characterized as other virus strains like HSV or Ad, which have been clinically developed as OVs since the 1990s [115].

\section{CVA21 (CAVATEK) + Ipilimumab and CVA21 + Pembrolizumab}

CAVATEK is an unmodified coxsackievirus A21 that demonstrated oncolytic activity in preclinical investigations $[23,115]$. CAVATEK binds to cancer cells by interacting with intercellular adhesion molecule 1 (ICAM-1) and decay-accelerating factor (DAF) [117]. For this reason, initial preclinical investigations examined the therapeutic effects of CAVATEK against metastatic melanoma cells, which are known to overexpress ICAM-1 $[118,119]$. Subsequently, the phase II trial CALM, with CAVATEK as a monotherapy against advanced melanoma patients, demonstrated that the virus induced antitumor responses, as evidenced by increased expression levels of IL- 8 and IFN- $\gamma$ in serum samples of melanoma patients following viral administration [120]. This evidence has led to four phase I combination clinical trials involving CAVATEK: two with the CTLA-4 inhibitor ipilimumab and two with the PD-1 inhibitor pembrolizumab.

The first phase I combination trial with CAVATEK and ipilimumab in advanced melanoma patients (NCT02307149) concluded that the combination therapy was well tolerated in a total of 16 patients and induced antitumor activity in both local, visceral, and non-visceral lesions in 12 patients that had failed previous lines of immunotherapy [121]. The second phase I clinical trial, CLEVER (NCT03408587), which combines CAVATEK and ipilimumab, aims to evaluate the combination therapy for its initial response in uveal melanoma that has metastasized to the liver.

In addition, another phase I combination trial evaluating CAVATEK and pembrolizumab, CAPRA (NCT02565992), was conducted in patients with advanced melanoma. In an interim abstract of the CAPRA trial, the authors reported the combination therapy to be well tolerated, with 11 of the 14 
patients showing an objective response rate of $73 \%$ and a disease control rate of $91 \%$ [122]. Furthermore, the authors noted tumor volume reductions in both injected and non-injected lesions, leading to the recruitment of additional patients (targeted patient number $=50$ ) [122]. Similar to the findings of the CAPRA trial, an interim report of the combination phase I trial of CAVATEK and pembrolizumab, KEYNOTE-200 (NCT02043665), reported the combination therapy to be generally well tolerated, with no reported DLT in six patients with advanced solid tumors [123].

\subsection{Reovirus}

Reoviruses are non-enveloped and double-stranded RNA viruses belonging to the Reoviridae family with icosahedral capsids [124]. Reoviruses are 75-80 $\mathrm{nm}$ in size [53] and replicate in the cytoplasm [124]. The most extensively developed oncolytic strain of reovirus is Type 3 Dearing virus (Reolysin), which has been investigated in more than 30 clinical trials [125]. Reolysin selectively replicates in and exerts oncolytic effect against cancer cells with activating Ras mutation, which is observed in approximately $30 \%$ of all human cancers [126,127].

\section{Reolysin (Pelareorep) + Pembrolizumab}

The immunostimulatory effects of Reolysin have been well characterized by preclinical investigations, setting a rationale for combining the virus with ICIs [128,129]. In support, combination of intratumoral administration of Reolysin and systemically administered anti-PD-1 ICI resulted in significantly prolonged survival in an immunocompetent murine melanoma tumor model compared to monotherapy treatment with either compound [129]. Further, Rajani et al. reported Reolysin injection to prime tumors toward PD-1 blockade, as evidenced by an enhanced $\mathrm{CD} 8^{+} \mathrm{T}$ cell Th1 antitumor response compared to that after PD-1 monotherapy [129]. Samson et al. reported a similar immunostimulatory effect with reovirus infection. Compared to untreated brain tumors, those infected with a reovirus infusion prior to undergoing debulking neurosurgery demonstrated a marked increase in tumor-infiltrating $\mathrm{CD}^{+}$cells in resected immunohistochemical specimens [130].

Additionally, preclinical and clinical studies evaluating Reolysin in combination with chemotherapeutic drugs such as gemcitabine, irinotecan, or taxanes have been shown to enhance viral replication and cytolytic effects [131-133]. Based on these results, a phase I trial combining Reolysin with one of three chemotherapeutic drugs (5-fluorouracil, gemcitabine, or irnotecan) followed by administration of the PD- 1 inhibitor pembrolizumab in patients with advanced pancreatic adenocarcinoma was evaluated (NCT02620423). Of the 10 patients that could be evaluated for therapeutic effects, three achieved long-term benefits from the triple combination therapy; in detail, one patient achieved a partial response that lasted up to 17.4 months after treatment, and two patients achieved stable disease for 9.1 and 4.1 months (median OS of all patients enrolled in this study was 3.1 months) [134]. Post-treatment tumor biopsies of two patients showed increased CD8+ T cell infiltration in comparison to pretreatment biopsies, suggesting that the TME of desmoplastic tumors and the well-characterized immunosuppressive TMEs of pancreatic tumors could be overcome by triple combination therapy. Patients that derived clinical benefit in this study showed elevated expression of LILRA4 and ICOS, which are key factors in the IFN- $\gamma$ response to reovirus infection, after pembrolizumab administration. This result shows that a virus-induced immune response in tumor tissues may be a critical factor in the synergy of OV with ICI therapy. Additionally, the trial compared peripheral blood at the time of pelareorep priming (cycle 1, day 8) versus that after administration of pembrolizumab (cycle 2, day 1). Greater clonal expansion of T cells during the pelareorep priming stage was associated with improved long-term patient outcomes compared to those achieved after pembrolizumab combination therapy, showing that the robust immune priming of TME by Reolysin was a prerequisite for patient response. Lastly, there was no immune-related toxicity following triple combination therapy, demonstrating that the addition of Reolysin to combined chemo- and immunotherapies is well tolerated [135]. 


\subsection{Vesicular Stomatitis Virus}

Vesicular stomatitis virus (VSV) belongs to the Rhabdoviridae family and is an enveloped, 11-kb, single-stranded RNA virus with a size of $70 \mathrm{~nm}$ [136]. Recombinant strains of VSV, such as VSV(Delta51)-NIS and VSV-IFN $\beta$, have shown oncolytic properties in preclinical myeloma models [137,138] and in other cancer models [139-142]. VSV exhibits wide species tropism, allowing preclinical validation in immunocompetent rodents [143]. Furthermore, Stojdl et al. have demonstrated attenuated versions of VSV, such as AV1 or AV2, to have oncolytic properties, as these viruses are capable of selective replication in IFN-deficient cancer cells, while normal cells have an intact IFN response to resist viral infection [144].

VSV-hIFN $\beta$-NIS + Avelumab and VSV-hIFN $\beta$-NIS + Pembrolizumab

VSV-hIFN $\beta$-NIS is an oncolytic VSV expressing human IFN- $\beta$ and sodium iodide symporter (NIS) reported to induce rapid and potent tumor remission following systemic therapy $[145,146]$. Several preclinical investigations of VSV-hIFN $\beta$-NIS have been performed in acute myeloid leukemia (AML) models, as recent preclinical and clinical studies have demonstrated the significant therapeutic value of OV against hematologic malignancies $[145,147,148]$. In particular, the virus has demonstrated the potential to induce an antitumoral immune response in AML as a monotherapy or in combination with the PD-L1 inhibitor $\mathrm{Ab}$, made evident by an increase in tumoral $\mathrm{CD} 4^{+}$and $\mathrm{CD} 8^{+} \mathrm{T}$ cell infiltration. Furthermore, Shen et al. demonstrated the depletion of $\mathrm{NK}$ or $\mathrm{CD} 8^{+}$immune cells to result in ineffective combination therapy, suggesting the need for induction of cellular antitumor immune responses to improve survival [146].

These preclinical findings led to the inclusion of VSV-hIFN $\beta$-NIS in two combination phase I trials: one trial combined it with an anti-PD-L1 Ab, avelumab, in patients with refractory metastatic solid tumors (NCT02923466), while the other combined it with an anti-PD1 Ab, pembrolizumab, in patients with refractory non-small-cell lung carcinoma (NSCLC) or head and neck squamous cell carcinoma (NCT03647163). As both trials are in the recruitment phase, no data have been published, and further investigation is needed on the safety profiles and antitumor effects of the combination trials [135].

\subsection{Maraba Virus}

Maraba virus (MV) is a member of the Rhabdovirus family with an RNA genome [149]. MVs are relatively simple viruses but possess a number of properties that suggest their use as OV agents. For example, MVs are rarely associated with human disease, and pre-existing immunity against MV is rare in most populations [148]. In addition, the entire life cycle of MV occurs in the cytoplasm, preventing the opportunity for insertional mutagenicity [150]. Furthermore, despite the small genome size of the virus at $11 \mathrm{~kb}$, MVs can be genetically manipulated for transgene insertion [150].

\section{MG1-MAGEA3 + Pembrolizumab and MG1-E6E7 + Atezolizumab}

Preclinical development of MV as an OV agent began with a genetically modified version of the wild type, MG1. Bourgeois-Daigneault et al. have shown that neoadjuvant treatment with MG1, prior to surgical tumor resection, improved survival and decreased both the size and number of subsequent lung metastases in triple negative breast cancer (TNBC) models [151]. Further, Zhang et al. demonstrated the intrinsic ability of attenuated MG1 to induce an NK cell-dependent antitumor response in a lung metastases model of melanoma [152]. Bourgeois-Daigneault et al. demonstrated that the antitumor immune response-inducing properties of MG1 can be further augmented by combination with anti-PD-1 or -CTLA-4 therapy, as the combination therapies induced more robust tumor growth inhibition than did the monotherapy controls [151].

MG1 has been investigated in clinical trials as an oncolytic cancer vaccine expressing MAGE-A3, which is a known tumor antigen selectively expressed in several types of tumors, such as NSCLC, melanoma, and certain hematological malignancies [89]. Specifically, preclinical work has demonstrated 
that primates primed with non-replicating Ad expressing MAGE-A3 (AdMA3) and boosted by oncolytic MG1-MAGEA3-induced MAGE-A3-specific CD4+ and CD8+ T cell activation [150]. This dual viral approach was investigated further as the basis of the first MG1-MAGEA3 clinical trial (NCT02285816), where it was administered with and without an AdMA3 in incurable MAGE-A3-expressing solid tumors. Interim reports of this trial have demonstrated AdMA3 followed by MG1-MAGEA3 to induce a potent antitumor immune response, confirming preclinical evidence reported by Pol et al. [153]. One potential concern for this strategy is that the function of MAGE-A3, along with those of similar family members MAGE-A2 and -A9, is relatively unknown and has conflicting reports. Some groups have demonstrated pro-tumorigenic effects and association with poor overall survival rate of antigen overexpression, while others have focused on the strong antitumor immune response-inducing potential of the antigen in vaccination strategies [153-155]. Despite the potential oncogenic activity of MAGE-A3, it is worth noting that recombinant MAGE-A3 protein administration in a large-scale randomized phase III trial was shown to be safe in NSCLC patients [156]. Due to these reasons, more in-depth safety analysis upon completion of the two phase I trials examining the therapeutic effect of MG1-MAGEA3 is eagerly awaited. MG1-MAGEA3 is also being investigated in combination with a PD-1 inhibitor, pembrolizumab, in patients with first standard therapy-resistant NSCLC (NCT02879760) or metastatic melanoma and cutaneous squamous cell skin cancer (NCT03773744). The NCT02879760 trial is underway, but no data have been reported, while the NCT03773744 trial is not yet recruiting participants.

Another MG1 oncolytic vaccine expressing an attenuated version of human papillomavirus (HPV) E6 and E7 proteins (MG1-E6E7) as therapeutic transgenes is under clinical investigation [157]. In a similar strategy to the MG1-MAGEA3 + AdMA3 tumor vaccination approach, tumors are first primed with replication-incompetent Ad expressing HPV E6 and E7 (AdE6E7), followed by the administration of oncolytic MG1-E6E7 and the anti-PD-L1 inhibitor atezolizumab in patients with advanced or recurrent HPV-associated tumors (NCT03618953). No data have been published, and further investigation is needed on the safety profiles and antitumor effects of the combination trial [158].

\subsection{Poliovirus}

Poliovirus belongs to the Picornaviridae family and has a 7.5-kb genome [159]. While the poliovirus is naturally oncolytic [160], it has been shown to be potently tropic toward CD155, an immune checkpoint molecule expressed in a wide range of malignant cells of solid tumors [161]. The pathogenicity, such as neurovirulence, of wild-type poliovirus is well known and must be adequately addressed before use as a therapeutic agent [161]. An example of an attenuated poliovirus is the Sabin vaccine, which was genetically modified to reduce its poliomyelitis effects while retaining its oncolytic activity [161].

PVSRIPO + Nivolumab and PVSRIPO + Atezolizumab

PVSRIPO is an oncolytic Sabin type 1 poliovirus that had an endogenous internal ribosome entry site (IRES) genetically replaced with a foreign IRES of human rhinovirus type 2 (HRV2) to attenuate the neurovirulence [161,162]. Preclinical studies of PVSRIPO demonstrated two notable findings: first, a single injection of the virus was equally effective in decreasing tumor burden compared to anti-PD-1 or anti-PD-L1 treatments in TNBC models [163]. Second, PVSRIPO in combination with anti-PD-1 or anti-PD-L1 therapy improved tumor growth inhibition compared to checkpoint blockade monotherapies [163].

Based on these results, PVSRIPO was evaluated for its safety as a monotherapy in a phase I trial in patients with RGBM (NCT01491893). A total of 61 patients received a dose of PVSRIPO without evidence of viral neuropathogenicity or virus shedding. However, $19 \%$ of the patients in the dose-expansion phase experienced grade 3 or higher PVSRIPO-related adverse events. The survival rate of patients treated with PVSRIPO was higher at 36 months after treatment compared to historical controls [164]. These results were the basis for two combination trials with PVSRIPO and ICIs. One of these trials investigated the combination of the virus with an anti-PD- 1 inhibitor, nivolumab, in patients 
with anti-PD-1 resistant melanoma (NCT04125719), while the other investigated the combination of PVSRIPO with a PD-L1 inhibitor, atezolizumab, in patients with RGBM (NCT03973879). However, both trials were withdrawn, although they are expected to be resubmitted, and no data have been published.

\subsection{Newcastle Disease Virus}

Newcastle disease virus (NDV) is a neurotropic virus with a 15-kb, single-stranded RNA genome and belongs to the Paramyxoviridae family [165]. NDV has been shown to be an effective oncolytic agent, reported to replicate up to 10,000 times faster in human cancer cells than in most normal human cells [166]. Further, Schirrmacher et al. have shown NDV-treated tumors to be infiltrated with T cells secreting IFN- $\gamma$ [167]. In addition, Koks et al. reported NDV infection to induce long-term survival and tumor-specific immunity in an orthotopic glioblastoma multiforme model in immunocompetent mice, while no therapeutic effects were seen in immunodeficient Rag2 (-/-) mice or mice depleted of $\mathrm{CD}^{+} \mathrm{T}$ cells [168].

A preclinical study revealed that intratumoral administration of NDV and systemic CTLA-4 blockade induced inflammatory responses and antitumor effects in both local and distant tumors via the induction of systemic and tumor-specific immune responses. Zamarin et al. also reported that localized administration of NDV induced a systemic tumor inflammatory response, as evidenced by the increased infiltration of activated effector T cells in non-injected distant tumors [165]. In addition, the authors found combination therapy of localized NDV and systemic CTLA-4 or PD-1 blockade to produce antigen-dependent tumor rejection in a tumor rechallenge model [166]. Zamarin et al. developed an NDV expressing an ICI molecule, ICOSL (NDV-ICOSL), which in combination with anti-CTLA-4 therapy induced a more effective rejection of distant tumors than NDV monotherapy, leading to the long-term survival of the majority of mice and providing protection against tumor relapse [169].

\section{MEDI5395 + Durvalumab}

MEDI5395 is a recombinant NDV encoding a GM-CSF transgene. MEDI5395 in a preclinical study was shown to preferentially replicate in tumor tissues, elevate PD-L1 expression, and induce an antitumor immune response [170]. Further, MEDI5395 treatment increased T cell recruitment and expression of IFN $\gamma$-inducible genes in vitro, suggesting immune activation of the TME. For these reasons, MEDI5395 has been recently entered in a phase I trial in combination with the PD-L1 inhibitor durvalumab (NCT03889275). However, as the trial is still in the recruitment phase, no data have been published, and further investigation is needed on the safety profiles and antitumor effects of the combination therapies.

\section{Conclusions}

The use of IO has changed cancer treatment in recent years. Despite ICI revolutionizing the cancer therapy field, it is largely ineffective in patients with cold tumors. To address this limitation, OVs in combination with ICIs can be a strategy to address the inefficacy of ICI against cold tumors, as these viruses can inflame the TME into a more immunologically favorable environment for cancer immunotherapeutics. The number of clinical trials investigating combinations of OVs and ICIs continues to rise, and most of the available results from these trials have demonstrated promising therapeutic potentials with good safety profiles. Other immunotherapeutics (like CAR-T and ICI) in combination with ICIs are well known to compound adverse events, whereas OVs do not, and this superior safety profile is particularly promising in IO. Due to the recency of many of these clinical trials, in-depth results are not available to the public, but many of the interim and preclinical results indicate strong synergism of the combination therapy approaches, as evidenced by increased migration of antitumor immune effector cells to tumor tissues and elevated expression of antitumor cytokines. The detailed results of these studies are highly anticipated, as they will provide much needed insights that will be critical to maximizing the therapeutic potential of $\mathrm{OV}$ and ICI combination therapies for 
treatment of intractable cancers. With increasing numbers of OV pipelines and ICIs entering clinical development, there is a strong potential for this strategy to revolutionize cancer treatment in the near future.

Author Contributions: Conceptualization, data search, writing, editing: J.K.H. and J.H. supervision: C.-O.Y. All authors have read and agreed to the published version of the manuscript.

Funding: This research received no external funding.

Acknowledgments: This work was supported by grants from the National Research Foundation of Korea (2016M3A9B5942352 to C.-O. Yun), Hanyang University General Research Grant (HY-2011-G-201100000001880) and GeneMedicine Project (GMPROJ-201905-01 to C.-O. Yun).

Conflicts of Interest: JinWoo Hong is a researcher at GeneMedicine. Chae-ok Yun is the CEO of GeneMedicine. The remaining authors declare no competing interests.

\section{Abbreviations}

IO

ICI

IgG1

CTLA-4

TME

OV

$\mathrm{Ab}$

PD-1

PD-L1

irAE

TIL

HMGB-1

TIM-3

APC

IFN- $\gamma$

IL-4

DC

LAG-3

MHC

Treg

RGBM

Gal-9

CEACAM1

PS

TIGIT

VISTA

PAMPS

TAA

DAMPS

IL-12

GM-CSF

HSV

MAGE-A3

NY-ESO-1

TNF- $\alpha$

IL-2

hTERT

MART

DLT

ICAM
Immuno-oncology

Immune checkpoint inhibitor

Immunoglobulin $\mathrm{G}$

Cytotoxic T-lymphocyte antigen-4

Tumor microenvironment

Oncolytic virus

Antibody

Programmed death 1

Programmed death-ligand 1

Immune-related adverse events

Tumor infiltrating lymphocyte

High-mobility group protein box 1

$\mathrm{T}$ cell immunoglobulin and mucin domain 3

Antigen-presenting cells

Interferon gamma

Interleukin

Dendritic cells

Lymphocyte-activation gene 3

Major histocompatibility complex

Regulatory T cells

Recurrent glioblastoma

Galectin-9

Carcinoembryonic antigen-related cell adhesion molecule 1

Phosphatidylserine

Tyrosine-based inhibition motif domain

V-domain Ig suppressor of $\mathrm{T}$ cell activation

Pathogen-associated molecular patterns

Tumor-associated antigens

Danger-associated molecular patterns

Interleukin 12

Granulocyte-macrophage colony-stimulating factor

Herpes simplex virus

Melanoma-associated antigen 3

New York esophageal squamous cell carcinoma 1

Tumor necrosis factor-alpha

Interleukin 2

Human telomerase reverse transcriptase

$\mathrm{T}$ cell-recognized melanoma antigen

Dose-limiting toxicity

Intercellular adhesion molecule 1 


$\begin{array}{ll}\text { DAF } & \text { Decay-accelerating factor } \\ \text { NIS } & \text { Sodium iodide symporter } \\ \text { NSCLS } & \text { Non-small-cell lung carcinoma } \\ \text { AML } & \text { Acute myeloid leukemia } \\ \text { TNBC } & \text { Triple negative breast cancer } \\ \text { IRES } & \text { Internal ribosome entry site } \\ \text { NDV } & \text { Newcastle disease virus } \\ \text { ICOS } & \text { Inducible co-stimulator }\end{array}$

\section{References}

1. Vaddepally, R.K.; Kharel, P.; Pandey, R.; Garje, R.; Chandra, A.B. Review of Indications of FDA-Approved Immune Checkpoint Inhibitors per NCCN Guidelines with the Level of Evidence. Cancers 2020, $12,738$. [CrossRef] [PubMed]

2. Darvin, P.; Toor, S.M.; Nair, V.S.; Elkord, E. Immune checkpoint inhibitors: Recent progress and potential biomarkers. Exp. Mol. Med. 2018, 50,1-11. [CrossRef] [PubMed]

3. Xin Yu, J.; Hubbard-Lucey, V.M.; Tang, J. Immuno-oncology drug development goes global. Nat. Rev. Drug Discov. 2019, 18, 899-900. [CrossRef]

4. Feng, Y.; Roy, A.; Masson, E.; Chen, T.T.; Humphrey, R.; Weber, J.S. Exposure-response relationships of the efficacy and safety of ipilimumab in patients with advanced melanoma. Clin. Cancer Res. 2013, 19, 3977-3986. [CrossRef]

5. Bonaventura, P.; Shekarian, T.; Alcazer, V.; Valladeau-Guilemond, J.; Valsesia-Wittmann, S.; Amigorena, S.; Caux, C.; Depil, S. Cold Tumors: A Therapeutic Challenge for Immunotherapy. Front. Immunol. 2019, 10, 168. [CrossRef] [PubMed]

6. Pardoll, D. The blockade of immune checkpoints in cancer immunotherapy. Nat. Rev. Cancer 2012, $252-264$. [CrossRef]

7. Zappasodi, R.; Merghoub, T.; Wolchok, J.D. Emerging Concepts for Immune Checkpoint Blockade-Based Combination Therapies. Cancer Cell 2018, 33, 581-598. [CrossRef]

8. Comin-Anduix, B.; Escuin-Ordinas, H.; Ibarrondo, F.J. Tremelimumab: Research and clinical development. OncoTargets Ther. 2016, 9, 1767-1776. [CrossRef]

9. Dempke, W.C.M.; Fenchel, K.; Uciechowski, P.; Dale, S.P. Second- and third-generation drugs for immuno-oncology treatment-The more the better? Eur. J. Cancer 2017, 74, 55-72. [CrossRef]

10. Woo, S.R.; Turnis, M.E.; Goldberg, M.V.; Bankoti, J.; Selby, M.; Nirschl, C.J.; Bettini, M.L.; Gravano, D.M.; Vogel, P.; Liu, C.L.; et al. Immune inhibitory molecules LAG-3 and PD-1 synergistically regulate T-cell function to promote tumoral immune escape. Cancer Res. 2012, 72, 917-927. [CrossRef]

11. Shayan, G.; Srivastava, R.; Li, J.; Schmitt, N.; Kane, L.P.; Ferris, R.L. Adaptive resistance to anti-PD1 therapy by TIM-3 upregulation is mediated by the PI3K-Akt pathway in head and neck cancer. Oncoimmunology 2017, 6, e1261779. [CrossRef] [PubMed]

12. Spiers, L.; Coupe, N.; Payne, M. Toxicities associated with checkpoint inhibitors-an overview. Rheumatology 2019, 58 (Suppl. 7), vii7-vii16. [CrossRef] [PubMed]

13. Jenkins, R.; Barbie, D.; Flaherty, K. Mechanisms of resistance to immune checkpoint inhibitors. Br. J. Cancer 2018, 118, 9-16. [CrossRef]

14. Shekarian, T.; Valsesia-Wittmann, S.; Brody, J.; Michallet, M.C.; Depil, S.; Caux, C.; Marabelle, A. Pattern recognition receptors: Immune targets to enhance cancer immunotherapy. Ann Oncol. 2017, 28, 1756-1766. [CrossRef] [PubMed]

15. Keenan, T.E.; Burke, K.P.; Van Allen, E.M. Genomic correlates of response to immune checkpoint blockade. Nat. Med. 2019, 25, 389-402. [CrossRef]

16. van Rooij, N.; van Buuren, M.M.; Philips, D.; Velds, A.; Toebes, M.; Heemskerk, B.; van Dijk, L.; Behjati, S.; Hilkmann, H.; Atmioui, D.; et al. Tumor exome analysis reveals neoantigen-specific T-cell reactivity in an ipilimumab-responsive melanoma. J. Clin. Oncol. 2013, 31, e439-e442. [CrossRef]

17. Le, D.T.; Durham, J.N.; Smith, K.N.; Wang, H.; Bartlett, B.; Aulakh, L.; Lu, S.; Kemberling, H.; Wilt, C.; Luber, B.; et al. Mismatch repair deficiency predicts response of solid tumors to PD-1 blockade. Science 2017, 357, 409-413. [CrossRef] [PubMed] 
18. Van Allen, E.M.; Miao, D.; Schilling, B.; Shukla, S.; Blank, C.; Zimmer, L.; Sucker, A.; Hillen, U.; Foppen, M.; Goldinger, S.; et al. Genomic correlates of response to CTLA-4 blockade in metastatic melanoma. Science 2015, 350, aad8366. [CrossRef]

19. Rizvi, N.A.; Hellmann, M.D.; Snyder, A.; Kvistborg, P.; Makarov, V.; Havel, J.; Lee, W.; Yuan, J.; Wong, P.; Ho, T.; et al. Cancer immunology. Mutational landscape determines sensitivity to PD-1 blockade in non-small cell lung cancer. Science 2015, 348, 124-128. [CrossRef]

20. Le, D.T.; Uram, J.N.; Wang, H.; Bartlett, B.R.; Kemberling, H.; Eyring, A.D.; Skora, A.D.; Luber, B.S.; Azad, N.S.; Laheru, D.; et al. PD-1 Blockade in Tumors with Mismatch-Repair Deficiency. N. Engl. J. Med. 2015, 372, 2509-2520. [CrossRef]

21. Hong, J.; Yun, C.O. Emergence of Ad-Mediated Combination Therapy Against Cancer: What to Expect? Curr. Cancer Drug Targets 2018, 18, 139-152. [CrossRef] [PubMed]

22. Chaurasiya, S.; Warner, S. Viroimmunotherapy for Colorectal Cancer: Clinical Studies. Biomedicines 2017, 5, 11. [CrossRef] [PubMed]

23. LaRocca, C.J.; Warner, S.G. Oncolytic viruses and checkpoint inhibitors: Combination therapy in clinical trials. Clin. Transl. Med. 2018, 7, 35. [CrossRef] [PubMed]

24. Marelli, G.; Howells, A.; Lemoine, N.R.; Wang, Y. Oncolytic Viral Therapy and the Immune System: A Double-Edged Sword Against Cancer. Front. Immunol. 2018, 26, 866. [CrossRef] [PubMed]

25. Guerra, L.; Bonetti, L.; Brenner, D. Metabolic Modulation of Immunity: A New Concept in Cancer Immunotherapy. Cell Rep. 2020, 32, 107848. [CrossRef]

26. Breitbach, C.J.; Lichty, B.D.; Bell, J.C. Oncolytic Viruses: Therapeutics with an Identity Crisis. EBioMedicine 2016, 9, 31-36. [CrossRef]

27. Melero, I.; Gato, M.; Shekarian, T.; Aznar, A.; Valsesia-Wittmann, S.; Caux, C.; Etxeberrria, I.; Teijeira, A.; Marabelle, A. Repurposing infectious disease vaccines for intratumoral immunotherapy. J. Immunother. Cancer 2020, 8, e000443. [CrossRef]

28. Lichty, B.D.; Breitbach, C.J.; Stojdl, D.F.; Bell, J.C. Going viral with cancer immunotherapy. Nat. Rev. Cancer 2014, 14, 559-567. [CrossRef]

29. Hong, J.; Yun, C.O. Overcoming the limitations of locally administered oncolytic virotherapy. BMC Biomed. Eng. 2019, 1, 17. [CrossRef]

30. Oh, E.; Choi, I.K.; Hong, J.; Yun, C.O. Oncolytic adenovirus coexpressing interleukin-12 and decorin overcomes Treg-mediated immunosuppression inducing potent antitumor effects in a weakly immunogenic tumor model. Oncotarget 2017, 8, 4730-4746. [CrossRef]

31. Choi, I.K.; Yun, C.O. Recent developments in oncolytic adenovirus-based immunotherapeutic agents for use against metastatic cancers. Cancer Gene Ther. 2013, 20, 70-76. [CrossRef] [PubMed]

32. Moon, C.Y.; Choi, J.W.; Kasala, D.; Jung, S.J.; Kim, S.W.; Yun, C.O. Dual tumor targeting with pH-sensitive and bioreducible polymer-complexed oncolytic adenovirus. Biomaterials 2015, 41, 53-68. [CrossRef] [PubMed]

33. Vacchelli, E.; Eggermont, A.; Sautès-Fridman, C.; Galon, J.; Zitvogel, L.; Kroemer, G.; Galluzzi, L. Trial watch: Oncolytic viruses for cancer therapy. Oncoimmunology 2013, 2, e24612. [CrossRef] [PubMed]

34. Patel, M.R.; Kratzke, R.A. Oncolytic virus therapy for cancer: The first wave of translational clinical trials. Transl. Res. 2013, 161, 355-364. [CrossRef]

35. Buonaguro, F.M.; Tornesello, M.L.; Izzo, F.; Buonaguro, L. Oncolytic virus therapies. Pharm. Pat. Anal. 2012, 1, 621-627. [CrossRef]

36. Nguyen, A.; Ho, L.; Wan, Y. Chemotherapy and Oncolytic Virotherapy: Advanced Tactics in the War against Cancer. Front. Oncol. 2014, 4, 145. [CrossRef]

37. Alberts, P.; Tilgase, A.; Rasa, A.; Bandere, K.; Venskus, D. The advent of oncolytic virotherapy in oncology: The Rigvir ${ }^{\circledR}$ story. Eur. J. Pharmacol. 2018, 837, 117-126. [CrossRef]

38. Liang, M. Oncorine, the World First Oncolytic Virus Medicine and its Update in China. Curr. Cancer Drug Targets 2018, 18, 171-176. [CrossRef]

39. Roberts, M.S.; Lorence, R.M.; Groene, W.S.; Bamat, M.K. Naturally oncolytic viruses. Curr. Opin. Mol. Ther. 2006, 8, 314-321.

40. Liang, M. Clinical development of oncolytic viruses in China. Curr. Pharm. Biotechnol. 2012, 13, $1852-1857$. [CrossRef]

41. Kirn, D. Clinical research results with d11520 (Onyx-015), a replication-selective adenovirus for the treatment of cancer: What have we learned? Gene Ther. 2001, 8, 89-98. [CrossRef] [PubMed] 
42. Ma, G.; Shimada, H.; Hiroshima, K.; Tada, Y.; Suzuki, N.; Tagawa, M. Gene medicine for cancer treatment: Commercially available medicine and accumulated clinical data in China. Drug Des. Devel. Ther. 2009, 2, 115-122. [CrossRef] [PubMed]

43. Rehman, H.; Silk, A.W.; Kane, M.P.; Kaufman, H.L. Into the clinic: Talimogene laherparepvec (T-VEC), a first-in-class intratumoral oncolytic viral therapy. J. Immunother. Cancer 2016, 4, 53. [CrossRef] [PubMed]

44. Andtbacka, R.H.I.; Collichio, F.; Harrington, K.J.; Middleton, M.R.; Downey, G.; Öhrling, K.; Kaufman, H.L. Final analyses of OPTiM: A randomized phase III trial of talimogene laherparepvec versus granulocyte-macrophage colony-stimulating factor in unresectable stage III-IV melanoma. J. Immunother. Cancer 2019, 7, 145. [CrossRef]

45. Russell, S.J.; Peng, K.W.; Bell, J.C. Oncolytic virotherapy. Nat Biotechnol. 2012, 30, 658-670. [CrossRef]

46. Kuryk, L.; Møller, A.W.; Jaderberg, M. Abscopal effect when combining oncolytic adenovirus and checkpoint inhibitor in a humanized NOG mouse model of melanoma. J. Med. Virol. 2019, 91, 1702-1706. [CrossRef]

47. Ribas, A.; Dummer, R.; Puzanov, I.; VanderWalde, A.; Andtbacka, R.H.I.; Michielin, O.; Olszanski, A.J.; Malvehy, J.; Cebon, J.; Fernandez, E.; et al. Oncolytic Virotherapy Promotes Intratumoral T Cell Infiltration and Improves Anti-PD-1 Immunotherapy. Cell 2017, 170, 1109-1119. [CrossRef]

48. Samson, A.; Scott, K.J.; Taggart, D.; West, E.; Wilson, E.; Nuovo, G.; Thomson, S.; Corns, R.; Mathew, R.; Fuller, M.; et al. Intravenous delivery of oncolytic reovirus to brain tumor patients immunologically primes for subsequent checkpoint blockade. Sci. Transl. Med. 2018, 10, eaam7577. [CrossRef]

49. Liu, Z.; Ravindranathan, R.; Kalinski, P.; Guo, Z.S.; Bartlett, D.L. Rational combination of oncolytic vaccinia virus and PD-L1 blockade works synergistically to enhance therapeutic efficacy. Nat. Commun. 2017, 8, 14754. [CrossRef]

50. Chen, L.; Han, X. Anti-PD-1/PD-L1 therapy of human cancer: Past, present, and future. J. Clin. Investig. 2015, 125, 3384-3391. [CrossRef]

51. Hodi, F.; Chiarion-Sileni, V.; Gonzalez, R.; Grob, J.; Rutkowski, P.; Cowey, C.; Lao, C.; Chadendorf, D.; Wagstaff, J.; Dummer, R.; et al. Nivolumab plus ipilimumab or nivolumab alone versus ipilimumab alone in advanced melanoma (CheckMate 067): 4-year outcomes of a multicentre, randomized, phase 3 trial. Lancet Oncol. 2018, 19, 1380-1492. [CrossRef]

52. Khanal, S.; Ghimire, P.; Dhamoon, A.S. The Repertoire of Adenovirus in Human Disease: The Innocuous to the Deadly. Biomedicines 2018, 6, 30. [CrossRef] [PubMed]

53. Kaufman, H.L.; Kohlhapp, F.J.; Zloza, A. Oncolytic viruses: A new class of immunotherapy drugs. Nat. Rev. Drug Discov. 2016, 15, 660. [CrossRef] [PubMed]

54. Buijs, P.R.; Verhagen, J.H.; van Eijck, C.H.; van den Hoogen, B.G. Oncolytic viruses: From bench to bedside with a focus on safety. Hum. Vaccines Immunother. 2015, 11, 1573-1584. [CrossRef]

55. Kasala, D.; Choi, J.W.; Kim, S.W.; Yun, C.O. Utilizing adenovirus vectors for gene delivery in cancer. Expert Opin. Drug Deliv. 2014, 11, 379-392. [CrossRef]

56. Halldén, G.; Portella, G. Oncolytic virotherapy with modified adenoviruses and novel therapeutic targets. Expert Opin. Ther. Targets. 2012, 16, 945-958. [CrossRef]

57. Robert-Guroff, M. Replicating and non-replicating viral vectors for vaccine development. Curr. Opin. Biotechnol. 2007, 18, 546-556. [CrossRef]

58. Hemminki, A. TILT Biotherapeutics. Hum. Vaccin. Immunother. 2017, 13, 970-971. [CrossRef]

59. Fueyo, J.; Alemany, R.; Gomez-Manzano, C.; Fuller, G.N.; Khan, A.; Conrad, C.A.; Liu, T.J.; Jiang, H.; Lemoine, M.G.; Suzuki, K.; et al. Preclinical characterization of the antiglioma activity of a tropism-enhanced adenovirus targeted to the retinoblastoma pathway. J. Natl. Cancer Inst. 2003, 95, 652-660. [CrossRef]

60. Fueyo, J.; Gomez-Manzano, C.; Alemany, R.; Lee, P.S.; McDonnell, T.J.; Mitlianga, P.; Shi, Y.X.; Levin, V.A.; Yung, W.K.; Kyritsis, A.P. A mutant oncolytic adenovirus targeting the Rb pathway produces anti-glioma effect in vivo. Oncogene 2000, 19, 2-12. [CrossRef]

61. Kiyokawa, J.; Wakimoto, H. Preclinical and Clinical Development of Oncolytic Adenovirus for the Treatment of Malignant Glioma. Oncolytic Virother. 2019, 8, 27-37. [CrossRef] [PubMed]

62. Wherry, E.J.; Kurachi, M. Molecular and cellular insights into T cell exhaustion. Nat. Rev. Immunol. 2015, 15, 486-499. [CrossRef] [PubMed] 
63. Garcia-Carbonero, R.; Salazar, R.; Duran, I.; Osman-Garcia, I.; Paz-Ares, L.; Bozada, J.; Boni, V.; Blac, C.; Seymour, L.; Beadle, J.; et al. Phase 1 study of intravenous administration of the chimeric adenovirus enadenotucirev in patients undergoing primary tumor resection. J. Immunother. Cancer 2017, 5, 71. [CrossRef] [PubMed]

64. Zadeh, G.; Lang, F.; Daras, M.; Cloughesy, T.; Colman, H.; Ong, S.; Ramakrishna, R.; Vogelbaum, M.; Groves, M.; Nassiri, F.; et al. ATIM-24. Interim results of a phase ii multicenter study of the conditionally replicative oncolytic adenovirus dnx-2401 with pembrolizumab (keytruda) for recurrent glioblastoma; captive study (keynote-192). Neuro. Oncol. 2018, 20 (Suppl. 6), vi6. [CrossRef]

65. Koski, A.; Kangasniemi, L.; Escutenaire, S.; Pesonen, S.; Cerullo, V.; Diaconu, I.; Nokisalmi, P.; Raki, M.; Rajecki, M.; Guse, K.; et al. Treatment of cancer patients with a serotype 5/3 chimeric oncolytic adenovirus expressing GMCSF. Mol. Ther. 2010, 18, 1874-1884. [CrossRef]

66. Ranki, T.; Pesonen, S.; Hemminki, A.; Partanen, K.; Kairemo, K.; Alanko, T.; Lundin, J.; Linder, N.; Turkki, R.; Ristimäki, A.; et al. Phase I study with ONCOS-102 for the treatment of solid tumors-An evaluation of clinical response and exploratory analyses of immune markers. J. Immunother. Cancer 2016, 4, 17. [CrossRef]

67. Ranki, T.; Joensuu, T.; Jäger, E.; Karbach, J.; Wahle, C.; Kairemo, K.; Alanko, T.; Partanen, K.; Turkki, R.; Linder, N.; et al. Local treatment of a pleural mesothelioma tumor with ONCOS-102 induces a systemic antitumor CD8+ T-cell response, prominent infiltration of CD8+ lymphocytes and Th1 type polarization. Oncoimmunology 2014, 3, e958937. [CrossRef]

68. Vassilev, L.; Ranki, T.; Joensuu, T.; Jäger, E.; Karbach, J.; Wahle, C.; Partanen, K.; Kairemo, K.; Alanko, T.; Turkki, R.; et al. Repeated intratumoral administration of ONCOS-102 leads to systemic antitumor CD8+ T-cell response and robust cellular and transcriptional immune activation at tumor site in a patient with ovarian cancer. Oncoimmunology 2015, 4, e1017702. [CrossRef]

69. Kuhn, I.; Harden, P.; Bauzon, M.; Chartier, C.; Nye, J.; Thorne, S.; Reid, T.; Ni, S.; Lieber, A.; Fisher, K.; et al. Directed evolution generates a novel oncolytic virus for the treatment of colon cancer. PLOS ONE 2008, 3, e2409. [CrossRef]

70. Marino, N.; Illingworth, S.; Kodialbail, P.; Patel, A.; Calderon, H.; Lear, R.; Fisher, K.; Champion, B.; Brown, A. Development of a versatile oncolytic virus platform for local intra-tumoural expression of therapeutic transgenes. PLoS ONE 2017, 12, e0177810. [CrossRef]

71. Di, Y.; Seymour, L.; Fisher, K. Activity of a group B oncolytic adenovirus (ColoAd1) in whole human blood. Gene Ther. 2014, 21, 440-443. [CrossRef] [PubMed]

72. Illingworth, S.; Di, Y.; Bauzon, M.; Lei, J.; Duffy, M.R.; Alvis, S.; Champion, B.; Lieber, A.; Hermiston, T.; Seymour, L.W.; et al. Preclinical Safety Studies of Enadenotucirev, a Chimeric Group B Human-Specific Oncolytic Adenovirus. Mol. Ther. Oncolytics 2017, 5, 62-74. [CrossRef]

73. Vogels, R.; Zuijdgeest, D.; van Rijnsoever, R.; Hartkoorn, E.; Damen, I.; de Béthune, M.P.; Kostense, S.; Penders, G.; Helmus, N.; Koudstaal, W.; et al. Replication-Deficient Human Adenovirus Type 35 Vectors for Gene Transfer and Vaccination: Efficient Human Cell Infection and Bypass of Preexisting Adenovirus Immunity. J. Virol. 2003, 77, 8263-8271. [CrossRef] [PubMed]

74. Holterman, L.; Vogels, R.; van der Vlugt, R.; Sieuwerts, M.; Grimbergen, J.; Kaspers, J.; Geelen, E.; van der Helm, E.; Lemckert, A.; Gillissen, G.; et al. Novel Replication-Incompetent Vector Derived from Adenovirus Type 11 (Ad11) for Vaccination and Gene Therapy: Low Seroprevalence and Non-Cross-Reactivity with Ad5. J. Virol. 2004, 78, 13207-13215. [CrossRef] [PubMed]

75. Wold, W.S.; Toth, K. Adenovirus vectors for gene therapy, vaccination and cancer gene therapy. Curr. Gene Ther. 2013, 13, 421-433. [CrossRef]

76. Sato-Dahlman, M.; Yamamoto, M. The Development of Oncoltyic Adenovirus Therapy in the Past and Future-For the Case of Pancreatic Cancer. Curr. Cancer Drug Targets. 2018, 18, 153-161. [CrossRef]

77. Sivanandam, V.; LaRocca, C.J.; Chen, N.G.; Fong, Y.; Warner, S.G. Oncolytic Viruses and Immune Checkpoint Inhibition: The Best of Both Worlds. Mol. Ther. Oncolytics 2019, 13, 93-106. [CrossRef]

78. Cervera-Carrascon, V.; Quixabeira, D.C.A.; Santos, J.M.; Havunen, R.; Zafar, S.; Hemminki, O.; Heiniö, C.; Munaro, E.; Siurala, M.; Sorsa, S.; et al. Tumor microenvironment remodeling by an engineered oncolytic adenovirus results in improved outcome from PD-L1 inhibition. Oncoimmunology 2020, 9, 1761229. [CrossRef]

79. Hemminki, O.; Dos Santos, J.M.; Hemminki, A. Oncolytic viruses for cancer immunotherapy. J. Hematol. Oncol. 2020, 13, 84. [CrossRef] 
80. Neuman, E.; Flemington, E.K.; Sellers, W.R.; Kaelin, W.G., Jr. Transcription of the E2F-1 gene is rendered cell cycle dependent by E2F DNA-binding sites within its promoter. Mol. Cell Biol. 1994, 14, 6607-6615. [CrossRef]

81. Zwicker, J.; Müller, R. Cell cycle-regulated transcription in mammalian cells. Prog. Cell Cycle Res. 1995, 1, 91-99. [CrossRef] [PubMed]

82. Takakura, M.; Nakamura, M.; Kyo, S.; Hashimoto, M.; Mori, N.; Ikoma, T.; Mizumoto, Y.; Fujiwara, T.; Urata, Y.; Inoue, M.; et al. Intraperitoneal administration of telomerase-specific oncolytic adenovirus sensitizes ovarian cancer cells to cisplatin and affects survival in a xenograft model with peritoneal dissemination. Cancer Gene Ther. 2010, 17, 11-19. [CrossRef] [PubMed]

83. Huang, J.H.; Zhang, S.N.; Choi, K.J.; Choi, I.K.; Kim, J.H.; Lee, M.G.; Kim, H.; Yun, C.O. Therapeutic and tumor-specific immunity induced by combination of dendritic cells and oncolytic adenovirus expressing IL-12 and 4-1BBL [published correction appears in Mol Ther. 2010 Feb;18,449. Lee, Mingul [corrected to Lee, Min-Geol]]. Mol Ther. 2010, 18, 264-274. [CrossRef] [PubMed]

84. Martin, N.T.; Bell, J.C. Oncolytic Virus Combination Therapy: Killing One Bird with Two Stones. Mol. Ther. 2018, 26, 1414-1422. [CrossRef] [PubMed]

85. Du, T.; Shi, G.; Li, Y.M.; Zhang, J.F.; Tian, H.W.; Wei, Y.Q.; Deng, H.; Yu, D.C. Tumor-specific oncolytic adenoviruses expressing granulocyte macrophage colony-stimulating factor or anti-CTLA4 antibody for the treatment of cancers. Cancer Gene Ther. 2014, 21, 340-348. [CrossRef]

86. Dias, J.D.; Hemminki, O.; Diaconu, I.; Hirvinen, M.; Bonetti, A.; Guse, K.; Escutenaire, S.; Kanerva, A.; Pesonen, S.; Löskog, A.; et al. Targeted cancer immunotherapy with oncolytic adenovirus coding for a fully human monoclonal antibody specific for CTLA-4. Gene Ther. 2012, 19, 988-998. [CrossRef]

87. Haanen, J. Converting Cold into Hot Tumors by Combining Immunotherapies. Cell 2017, 170, $1055-1056$. [CrossRef]

88. Rojas, J.J.; Gimenez-Alejandre, M.; Gil-Hoyos, R.; Cascallo, M.; Alemany, R. Improved systemic antitumor therapy with oncolytic adenoviruses by replacing the fiber shaft HSG-binding domain with RGD. Gene Ther. 2012, 19, 453-457. [CrossRef]

89. Chiu, M.; Armstrong, E.J.L.; Jennings, V.; Foo, S.; Crespo-Rodriguez, E.; Bozhanova, G.; Patin, E.C.; McLaughlin, M.; Mansfield, D.; Baker, G.; et al. Combination therapy with oncolytic viruses and immune checkpoint inhibitors. Expert Opin. Biol. Ther. 2020, 20, 635-652. [CrossRef]

90. Hartkopf, A.D.; Fehm, T.; Wallwiener, D.; Lauer, U. Oncolytic virotherapy of gynecologic malignancies. Gynecol. Oncol. 2011, 120, 302-310. [CrossRef]

91. De Clercq, E. Antiviral drugs in current clinical use. J. Clin. Virol. 2004, 30, 115-133. [CrossRef] [PubMed]

92. Rosenfeld, M.R.; Meneses, P.; Dalmau, J.; Drobnjak, M.; Cordon-Cardo, C.; Kaplitt, M.G. Gene transfer of wild-type p53 results in restoration of tumor-suppressor function in a medulloblastoma cell line. Neurology 1995, 45, 1533-1539. [CrossRef] [PubMed]

93. Kim, S.H.; Carew, J.F.; Kooby, D.A.; Shields, J.; Entwisle, C.; Patel, S.; Shah, J.P.; Fong, Y. Combination gene therapy using multiple immunomodulatory genes transferred by a defective infectious single-cycle herpes virus in squamous cell cancer. Cancer Gene Ther. 2000, 7, 1279-1285. [CrossRef] [PubMed]

94. Tung, C.; Federoff, H.J.; Brownlee, M.; Karpoff, H.; Weigel, T.; Brennan, M.F.; Fong, Y. Rapid production of interleukin-2-secreting tumor cells by herpes simplex virus-mediated gene transfer: Implications for autologous vaccine production. Hum. Gene Ther. 1996, 7, 2217-2224. [CrossRef] [PubMed]

95. Kanno, H.; Hattori, S.; Sato, H.; Murata, H.; Huang, F.H.; Hayashi, A.; Suzuki, N.; Yamamoto, I.; Kawamoto, S.; Minami, M.; et al. Experimental gene therapy against subcutaneously implanted glioma with a herpes simplex virus-defective vector expressing interferon-gamma. Cancer Gene Ther. 1999, 6, 147-154. [CrossRef] [PubMed]

96. Liu, B.L.; Robinson, M.; Han, Z.Q.; Branston, R.H.; English, C.; Reay, P.; McGrath, Y.; Thomas, S.K.; Thornton, M.; Bullock, P.; et al. ICP34.5 deleted herpes simplex virus with enhanced oncolytic, immune stimulating, and anti-tumour properties. Gene Ther. 2003, 10, 292-303. [CrossRef] [PubMed]

97. Kohlhapp, F.J.; Kaufman, H.L. Molecular Pathways: Mechanism of Action for Talimogene Laherparepvec, a New Oncolytic Virus Immunotherapy. Clin. Cancer Res. 2016, 22, 1048-1054. [CrossRef]

98. Andtbacka, R.H.; Kaufman, H.L.; Collichio, F.; Amatruda, T.; Senzer, N.; Chesney, J.; Delman, K.A.; Spitler, L.E.; Puzanov, I.; Agarwala, S.S.; et al. Talimogene Laherparepvec Improves Durable Response Rate in Patients With Advanced Melanoma. J. Clin. Oncol. 2015, 33, 2780-2788. [CrossRef] 
99. Kaufman, H.L.; Kim, D.W.; DeRaffele, G.; Mitcham, J.; Coffin, R.S.; Kim-Schulze, S. Local and distant immunity induced by intralesional vaccination with an oncolytic herpes virus encoding GM-CSF in patients with stage IIIc and IV melanoma. Ann. Surg. Oncol. 2010, 17, 718-730. [CrossRef]

100. Dummer, R.; Hoeller, C.; Gruter, I.P.; Michielin, O. Combining talimogene laherparepvec with immunotherapies in melanoma and other solid tumors. Cancer Immunol. Immunother. 2017, 66, 683-695. [CrossRef]

101. Puzanov, I.; Milhem, M.M.; Minor, D.; Hamid, O.; Li, A.; Chen, L.; Chastain, M.; Gorski, K.; Anderson, A.; Chou, J.; et al. Talimogene Laherparepvec in Combination with Ipilimumab in Previously Untreated, Unresectable Stage IIIB-IV Melanoma. J. Clin. Oncol. 2016, 34, 2619-2626. [CrossRef] [PubMed]

102. Eissa, I.R.; Naoe, Y.; Bustos-Villalobos, I.; Ichinose, T.; Tanaka, M.; Zhiwen, W.; Mukoyama, N.; Morimoto, T.; Miyajima, N.; Hitoki, H.; et al. Genomic Signature of the Natural Oncolytic Herpes Simplex Virus HF10 and Its Therapeutic Role in Preclinical and Clinical Trials. Front Oncol. 2017. [CrossRef] [PubMed]

103. Ng Tang, D.; Shen, Y.; Sun, J.; Wen, S.; Wolchok, J.D.; Yuan, J.; Allison, J.P.; Sharma, P. Increased frequency of ICOS+ CD4 T cells as a pharmacodynamic biomarker for anti-CTLA-4 therapy. Cancer Immunol. Res. 2013, 1, 229-234. [CrossRef] [PubMed]

104. Nakayama, T.; Yamashita, M.; Suzuki, T.; Shimomura, M.; Nakatsura, T.; Aoki, K.; Yamamoto, N.; Yamazaki, N.; Isei, T.; Uhara, H.; et al. Immunological impact of canerpaturev (C-REV, formerly HF10), an oncolytic viral immunotherapy, with or without ipilimumab (Ipi) for advanced solid tumor patients (pts). J. Clin. Oncol. 2019, 37 (Suppl. 15). [CrossRef]

105. Fujisawa, Y.; Yoshino, K.; Otsuka, A.; Funakoshi, T.; Uchi, H.; Fujimura, T.; Matsushita, S.; Hata, H.; Okuhira, H.; Tanaka, R.; et al. Retrospective study of advanced melanoma patients treated with ipilimumab after nivolumab: Analysis of 60 Japanese patients. J Dermatol. Sci. 2018, 89, 60-66. [CrossRef]

106. Haddad, D. Genetically Engineered Vaccinia Viruses As Agents for Cancer Treatment, Imaging, and Transgene Delivery. Front. Oncol. 2017, 7, 96. [CrossRef]

107. Al Yaghchi, C.; Zhang, Z.; Alusi, G.; Lemoine, N.R.; Wang, Y. Vaccinia virus, a promising new therapeutic agent for pancreatic cancer. Immunotherapy 2015, 7, 1249-1258. [CrossRef]

108. Breitbach, C.J.; Bell, J.C.; Hwang, T.H.; Kirn, D.H.; Burke, J. The emerging therapeutic potential of the oncolytic immunotherapeutic Pexa-Vec (JX-594). Oncolytic Virother. 2015, 4, 25-31. [CrossRef]

109. Hengstschläger, M.; Pfeilstöcker, M.; Wawra, E. Thymidine kinase expression. A marker for malignant cells. Adv. Exp. Med. Biol. 1998, 431, 455-460. [CrossRef]

110. Breitbach, C.J.; Arulanandam, R.; De Silva, N.; Thorne, S.H.; Patt, R.; Daneshmand, M.; Moon, A.; Ilkow, C.; Burke, J.; Hwang, T.H.; et al. Oncolytic vaccinia virus disrupts tumor-associated vasculature in humans. Cancer Res. 2013, 73, 1265-1275. [CrossRef]

111. Anthoney, A.; Samson, A.; West, E.; Turnbull, S.J.; Scott, K.; Tidswell, E.; Kingston, J.; Johnpulle, M.; Noutch, S.; Bendjama, K.; et al. Single intravenous preoperative administration of the oncolytic virus Pexa-Vec to prime anti-tumor immunity. J. Clin. Oncol. 2018, 36 (Suppl. 15), 3092. [CrossRef]

112. Breitbach, C.; Parato, K.; Burke, J.; Hwang, T.H.; Bell, J.; Kirn, D. Pexa-Vec double agent engineered vaccinia: Oncolytic and active immunotherapeutic. Curr. Opin. Virol. 2015, 13, 49-54. [CrossRef] [PubMed]

113. Pol, J.G.; Lévesque, S.; Workenhe, S.T.; Gujar, S.; Bouef, F.; Clements, D.; Fahrner, J.E.; Fend, L.; Bell, J.; Mossman, K.; et al. Trial Watch: Oncolytic viro-immunotherapy of hematologic and solid tumors. Oncoimmunology 2018, 7, e1503032. [CrossRef] [PubMed]

114. Chon, H.J.; Lee, W.S.; Yang, H.; Kong, S.J.; Lee, N.K.; Moon, E.S.; Choi, J.; Han, E.C.; Kim, J.H.; Ahn, J.B.; et al. Tumor Microenvironment Remodeling by Intratumoral Oncolytic Vaccinia Virus Enhances the Efficacy of Immune-Checkpoint Blockade. Clin. Cancer Res. 2019, 25, 1612-1623. [CrossRef]

115. Bradley, S.; Jakes, A.D.; Harrington, K.; Pandha, H.; Melcher, A.; Errington-Mais, F. Applications of coxsackievirus A21 in oncology. Oncolytic Virother. 2014, 3, 47-55. [CrossRef] [PubMed]

116. Au, G.G.; Beagley, L.G.; Haley, E.S.; Barry, R.D.; Shafren, D.R. Oncolysis of malignant human melanoma tumors by Coxsackieviruses A13, A15 and A18. Virol. J. 2011, 8, 22. [CrossRef] [PubMed]

117. Shafren, D.R.; Dorahy, D.J.; Ingham, R.A.; Burns, G.F.; Barry, R.D. Coxsackievirus A21 binds to decay-accelerating factor but requires intercellular adhesion molecule 1 for cell entry. J. Virol. 1997, 71, 4736-4743. [CrossRef] [PubMed] 
118. Shafren, D.R.; Au, G.G.; Nguyen, T.; Newcombe, N.G.; Haley, E.S.; Beagley, L.; Johansson, E.S.; Hersey, P.; Barry, R.D. Systemic therapy of malignant human melanoma tumors by a common cold-producing enterovirus, coxsackievirus a21. Clin. Cancer Res. 2004, 10, 53-60. [CrossRef]

119. Au, G.G.; Lindberg, A.M.; Barry, R.D.; Shafren, D.R. Oncolysis of vascular malignant human melanoma tumors by Coxsackievirus A21. Int. J. Oncol. 2005, 26, 1471-1476. [CrossRef]

120. Andtbacaka, R.; Shafren, D.; Grose, M.; Post, L.; Weisberg, J. Abstract 2939: CAVATAK-mediated oncolytic immunotherapy in advanced melanoma patients. Cancer Res. 2014, 74 (Suppl. 19). [CrossRef]

121. 121. Curti, B.; Richards, J.; Faries, M.; Andthbacaka, R.; Grose, M.; Karpathy, R.; Shafren, D. The MITCI (phase 1b) study: A novel immunotherapy combination of coxsackievirus A21 and ipilimumab in patients with advanced melanoma. Ann. Oncol. 2016, 27, VI360. [CrossRef]

122. Silk, A.; Kaufman, H.; Gabrail, N.; Mehnert, J.; Bryan, J.; Norrell, J.; Medina, D.; Bommareddy, P.; Shafren, D.; Grose, M.; et al. Abstract CT026: Phase 1b study of intratumoral Coxsackievirus A21 (CVA21) and systemic pembrolizumab in advanced melanoma patients: Interim results of the CAPRA clinical trial. Cancer Res. 2017, 77 (Suppl. 13). [CrossRef]

123. Pandha, H.; Ralph, C.; Harrington, K.; Curti, B.; Sanborn, R.; Akerley, W.; Gupta, S.; Rudin, C.; Rosenberg, J.; Kaufman, D.; et al. Keynote-200 phase 1b: A novel combination study of intravenously delivered coxsackievirus A21 and pembrolizumab in advanced cancer patients. J. Clin. Oncol. 2017, 35 (Suppl. 15). [CrossRef]

124. Phillips, M.B.; Stuart, J.D.; Rodríguez Stewart, R.M.; Berry, J.T.; Mainou, B.A.; Boehme, K.W. Current understanding of reovirus oncolysis mechanisms. Oncolytic Virother. 2018, 7, 53-63. [CrossRef]

125. Gong, J.; Mita, M.M. Activated ras signaling pathways and reovirus oncolysis: An update on the mechanism of preferential reovirus replication in cancer cells. Front. Oncol. 2014, 4, 167. [CrossRef]

126. Shmulevitz, M.; Marcato, P.; Lee, P.W. Unshackling the links between reovirus oncolysis, Ras signaling, translational control and cancer. Oncogene 2005, 24, 7720-7728. [CrossRef]

127. Gong, J.; Sachdev, E.; Mita, A.C.; Mita, M.M. Clinical development of reovirus for cancer therapy: An oncolytic virus with immune-mediated antitumor activity. World J. Methodol. 2016, 6, 25-42. [CrossRef]

128. Chakrabarty, R.; Tran, H.; Selvaggi, G.; Hagerman, A.; Thompson, B.; Coffey, M. The oncolytic virus, pelareorep, as a novel anticancer agent: A review. Investig. New Drugs. 2015, 33, 761-774. [CrossRef]

129. Rajani, K.; Parrish, C.; Kottke, T.; Thompson, J.; Zaidi, S.; Ilett, L.; Shim, K.G.; Diaz, R.M.; Pandha, H.; Harrington, K.; et al. Combination Therapy with Reovirus and Anti-PD-1 Blockade Controls Tumor Growth Through Innate and Adaptive Immune Responses. Mol. Ther. 2016, 24, 166-174. [CrossRef]

130. Samson, A.; Bentham, M.J.; Scott, K.; Nuovo, G.; Bloy, A.; Appleton, E.; Adair, R.; Dave, R.; Peckham-Cooper, A.; Toogood, G.; et al. Oncolytic reovirus as a combined antiviral and anti-tumour agent for the treatment of liver cancer. Gut 2018, 67, 562-573. [CrossRef]

131. Lolkema, M.P.; Arkenau, H.T.; Harrington, K.; Roxburgh, P.; Morrison, R.; Roulstone, V.; Twigger, K.; Coffey, M.; Mettinger, K.; Gill, G.; et al. A phase I study of the combination of intravenous reovirus type 3 Dearing and gemcitabine in patients with advanced cancer. Clin. Cancer Res. 2011, 17, 581-588. [CrossRef] [PubMed]

132. Gujar, S.A.; Clements, D.; Dielschneider, R.; Helson, E.; Marcato, P.; Lee, P.W. Gemcitabine enhances the efficacy of reovirus-based oncotherapy through anti-tumour immunological mechanisms. Br. J. Cancer 2014, 110, 83-93. [CrossRef] [PubMed]

133. Mahalingam, D.; Wilkinson, G.; Eng, K.; Fields, P.; Raber, P.; Moseley, J.; Cheetham, K.; Coffey, M.; Nuovo, G.; Kalinski, P.; et al. Pembrolizumab in Combination with the Oncolytic Virus Pelareorep and Chemotherapy in Patients with Advanced Pancreatic Adenocarcinoma: A Phase Ib Study. Clin. Cancer Res. 2019, 71-81. [CrossRef] [PubMed]

134. Mahalingam, D.; Fountzilas, C.; Moseley, J.; Noronha, N.; Cheetham, K.; Dzugalo, A.; Nuovo, G.; Gutierrez, A.; Arora, S. A study of pelareorep in combination with pembrolizumab and chemotherapy in patients (pts) with relapsed metastatic adenocarcinoma of the pancreas (MAP). J. Clin. Oncol. 2018, 36, 283. [CrossRef]

135. Mahalingam, D.; Fountzilas, C.; Moseley, J.; Noronha, N.; Cheetham, K.; Dzugalo, A.; Nuovo, G.; Gutierrez, A.; Arora, S. A study of REOLYSIN in combination with pembrolizumab and chemotherapy in patients (pts) with relapsed metastatic adenocarcinoma of the pancreas (MAP). J. Clin. Oncol. 2017, 35 (Suppl. 15). [CrossRef]

136. Strauss, J.H.; Strauss, E.G. Minus-Strand RNA Viruses. Viruses Hum. Dis. 2008, 137-191. [CrossRef] 
137. Lichty, B.D.; Stojdl, D.F.; Taylor, R.A.; Miller, L.; Frenkel, I.; Atkins, H.; Bell, J.C. Vesicular stomatitis virus: A potential therapeutic virus for the treatment of hematologic malignancy. Hum. Gene Ther. 2004, 15, 821-831. [CrossRef] [PubMed]

138. Goe Naik, S.; Nace, R.; Barber, G.N.; Russell, S.J. Potent systemic therapy of multiple myeloma utilizing oncolytic vesicular stomatitis virus coding for interferon- $\beta$. Cancer Gene Ther. 2012, 19, 443-450. [CrossRef]

139. Hastie, E.; Besmer, D.M.; Shah, N.R.; Murphy, M.A.; Moerdyk-Schauwecker, M.; Molestina, C.; Roy, L.; Curry, J.; Mukherjee, P.; Grdzelishvili, V.; et al. Oncolytic vesicular stomatitis virus in an immunocompetent model of MUC1-positive or MUC1-null pancreatic ductal adenocarcinoma. J. Virol. 2013, 87, 10283-10294. [CrossRef]

140. Wu, L.; Huang, T.G.; Meseck, M.; Altomonte, J.; Ebert, O.; Shinozaki, K.; García-Sastre, A.; Fallon, J.; Mandeli, J.; Woo, S.L. rVSV(M Delta 51)-M3 is an effective and safe oncolytic virus for cancer therapy. Hum. Gene Ther. 2008, 19, 635-647. [CrossRef]

141. Wollmann, G.; Rogulin, V.; Simon, I.; Rose, J.K.; van den Pol, A.N. Some attenuated variants of vesicular stomatitis virus show enhanced oncolytic activity against human glioblastoma cells relative to normal brain cells. J. Virol. 2010, 84, 1563-1573. [CrossRef] [PubMed]

142. Stewart, J.H.; Ahmed, M.; Northrup, S.A.; Willingham, M.; Lyles, D.S. Vesicular stomatitis virus as a treatment for colorectal cancer. Cancer Gene Ther. 2011, 18, 837-849. [CrossRef] [PubMed]

143. Naik, S.; Nace, R.; Federspiel, M.J.; Barber, G.N.; Peng, K.W.; Russell, S.J. Curative one-shot systemic virotherapy in murine myeloma. Leukemia 2012, 26, 1870-1878. [CrossRef] [PubMed]

144. Stojdl, D.F.; Lichty, B.D.; ten Oever, B.R.; Paterson, J.M.; Power, A.T.; Knowles, S.; Marius, R.; Reynard, J.; Poliquin, L.; Atkins, H.; et al. VSV strains with defects in their ability to shutdown innate immunity are potent systemic anti-cancer agents. Cancer Cell 2003, 4, 263-275. [CrossRef]

145. Velazquez-Salinas, L.; Naik, S.; Pauszek, S.J.; Peng, K.W.; Russell, S.J.; Rodriguez, L.L. Oncolytic Recombinant Vesicular Stomatitis Virus (VSV) Is Nonpathogenic and Nontransmissible in Pigs, a Natural Host of VSV. Hum. Gene Ther. Clin. Dev. 2017, 28, 108-115. [CrossRef]

146. Shen, W.; Patnaik, M.M.; Ruiz, A.; Russell, S.J.; Peng, K.W. Immunovirotherapy with vesicular stomatitis virus and PD-L1 blockade enhances therapeutic outcome in murine acute myeloid leukemia. Blood 2016, 127, 1449-1458. [CrossRef]

147. Stief, A.E.; McCart, J.A. Oncolytic virotherapy for multiple myeloma. Expert Opin. Biol. Ther. 2008, 8, 463-473. [CrossRef]

148. Bais, S.; Bartee, E.; Rahman, M.M.; McFadden, G.; Cogle, C.R. Oncolytic virotherapy for hematological malignancies. Adv. Virol. 2012, 2012, 186512. [CrossRef]

149. Brun, J.; McManus, D.; Lefebvre, C.; Hu, K.; Falls, T.; Atkins, H.; Bell, J.; McCart, J.; Mahoney, D.; Stojdl, D. Identification of genetically modified Maraba virus as an oncolytic rhabdovirus. Mol. Ther. 2010, 18, 1440-1449. [CrossRef]

150. Pol, J.G.; Atherton, M.J.; Bridle, B.W.; Stephenson, K.B.; Le Boeuf, F.; Hummel, J.L.; Martin, C.G.; Pomoransky, J.; Breitbach, C.J.; Diallo, J.S.; et al. Development and applications of oncolytic Maraba virus vaccines. Oncolytic Virother. 2018, 7, 117-128. [CrossRef]

151. Bourgeois-Daigneault, M.C.; Roy, D.G.; Aitken, A.S.; El Sayes, N.; Martin, N.T.; Varette, O.; Falls, T.; St-Germain, L.E.; Pelin, A.; Lichty, B.D.; et al. Neoadjuvant oncolytic virotherapy before surgery sensitizes triple-negative breast cancer to immune checkpoint therapy. Sci. Transl. Med. 2018, 10, eaao1641. [CrossRef] [PubMed]

152. Zhang, J.; Tai, L.H.; Ilkow, C.S.; Alkayyal, A.A.; Ananth, A.A.; de Souza, C.; Wang, J.; Sahi, S.; Ly, L.; Lefebvre, C.; et al. Maraba MG1 virus enhances natural killer cell function via conventional dendritic cells to reduce postoperative metastatic disease. Mol. Ther. 2014, 22, 1320-1332. [CrossRef]

153. Pol, J.G.; Acuna, S.A.; Yadollahi, B.; Tang, N.; Stephenson, K.; Atherton, M.; Hanwell, D.; El-Warrack, A.; Goldstein, A.; Moloo, B.; et al. Preclinical evaluation of a MAGE-A3 vaccination utilizing the oncolytic Maraba virus currently in first-in-human trials. Oncoimmunology 2018, 8, e1512329. [CrossRef]

154. Das, B.; Senapati, S. Functional and mechanistic studies reveal MAGEA3 as a pro-survival factor in pancreatic cancer cells. J. Exp. Clin. Cancer Res. 2019, 38, 294. [CrossRef] [PubMed]

155. Zajac, P.; Schultz-Thater, E.; Tornillo, L.; Sadowski, C.; Trella, E.; Mengus, C.; Iezzi, G.; Spagnoli, G.C. MAGE-A Antigens and Cancer Immunotherapy. Front Med. 2017, 4, 18. [CrossRef] [PubMed] 
156. Vansteenkiste, J.F.; Cho, B.C.; Vanakesa, T.; De Pas, T.; Zielinski, M.; Kim, M.S.; Jassem, J.; Yoshimura, M.; Dahabreh, J.; Nakayama, H.; et al. Efficacy of the MAGE-A3 cancer immunotherapeutic as adjuvant therapy in patients with resected MAGE-A3-positive non-small-cell lung cancer (MAGRIT): A randomised, double-blind, placebo-controlled, phase 3 trial. Lancet Oncol. 2016, 17, 822-835. [CrossRef]

157. Atherton, M.J.; Stephenson, K.B.; Nikota, J.K.; Hu, Q.N.; Nguyen, A.; Wan, Y.; Lichty, B.D. Preclinical development of peptide vaccination combined with oncolytic MG1-E6E7 for HPV-associated cancer. Vaccine 2018, 36, 2181-2192. [CrossRef]

158. Narisawa-Saito, M.; Kiyono, T. Basic mechanisms of high-risk human papillomavirus-induced carcinogenesis: Roles of E6 and E7 proteins. Cancer Sci. 2007, 98, 1505-1511. [CrossRef]

159. Burrill, C.P.; Strings, V.R.; Andino, R. Poliovirus: Generation, quantification, propagation, purification, and storage. Curr. Protoc. Microbiol. 2013, 29, 15H.1.1-15H.1.27. [CrossRef]

160. Denniston, E.; Crewdson, H.; Rucinsky, N.; Stegman, A.; Remenar, D.; Moio, M.; Clark, B.; Higginbotham, A.; Keffer, R.; Brammer, S.; et al. The Practical Consideration of Poliovirus as an Oncolytic Virotherapy. Am. J. Virol. 2016, 5, 1-7. [CrossRef]

161. Gromeier, M.; Nair, S.K. Recombinant Poliovirus for Cancer Immunotherapy. Annu. Rev. Med. 2018, 69, 289-299. [CrossRef] [PubMed]

162. Jammal, M.P.; Michelin, M.A.; Nomelini, R.S.; Murta, E.F.C. Recombinant poliovirus for cancer immunotherapy. Ann. Transl. Med. 2018, 6, 368. [CrossRef] [PubMed]

163. Force, J.; Holl, E.; Brown, M.; Marcom, P.; Grimm, L.; Boczkowski, D.; Franzier, V.; Herndon, J.; Bigner, D.; Hwang, E.S.; et al. Recombinant oncolytic poliovirus combined with checkpoint blockade for breast cancer therapy. J. Clin. Oncol. 2018, 36 (Suppl. 15). [CrossRef]

164. Desjardins, A.; Gromeier, M.; Herndon, J.E.; Beaubier, N.; Bolognesi, D.P.; Friedman, A.H.; Friedman, H.S.; McSherry, F.; Muscat, A.M.; Nair, S.; et al. Recurrent Glioblastoma Treated with Recombinant Poliovirus. N. Engl. J. Med. 2018, 379, 150-161. [CrossRef] [PubMed]

165. Reichard, K.W.; Lorence, R.M.; Cascino, C.J.; Peeples, M.E.; Walter, R.J.; Fernando, M.B.; Reyes, H.M.; Greager, J.A. Newcastle disease virus selectively kills human tumor cells. J. Surg. Res. 1992, 52, 448-453. [CrossRef]

166. Phuangsab, A.; Lorence, R.M.; Reichard, K.W.; Peeples, M.E.; Walter, R.J. Newcastle disease virus therapy of human tumor xenografts: Antitumor effects of local or systemic administration. Cancer Lett. 2001, 172, 27-36. [CrossRef]

167. Schirrmacher, V. Oncolytic Newcastle disease virus as a prospective anti-cancer therapy. A biologic agent with potential to break therapy resistance. Expert Opin. Biol. Ther. 2015, 15, 1757-1771. [CrossRef]

168. Koks, C.A.; Garg, A.D.; Ehrhardt, M.; Riva, M.; Vandenberk, L.; Boon, L.; De Vleeschouwer, S.; Agostinis, P.; Graf, N.; Van Gool, S.W. Newcastle disease virotherapy induces long-term survival and tumor-specific immune memory in orthotopic glioma through the induction of immunogenic cell death. Int. J. Cancer 2015, 136, E313-E325. [CrossRef]

169. Zamarin, D.; Holmgaard, R.B.; Ricca, J.; Plitt, T.; Palese, P.; Sharma, P.; Merghoub, T.; Wolchok, J.D.; Allison, J.P. Intratumoral modulation of the inducible co-stimulator ICOS by recombinant oncolytic virus promotes systemic anti-tumour immunity. Nat. Commun. 2017, 8, 14340. [CrossRef]

170. Dy, G.; Davar, D.; Galanis, E.; Townsley, D.; Karanovic, D.; Schwaederle, M.; Kelly, B.; Zamarin, D.; Borad, M.; Harrington, K. Abstract CT244: A phase 1 study of IV MEDI5395, an oncolytic virus, in combination with durvalumab in patients with advanced solid tumors. Cancer Res. 2020, 80 (Suppl. 16). [CrossRef]

Publisher's Note: MDPI stays neutral with regard to jurisdictional claims in published maps and institutional affiliations.

(C) 2020 by the authors. Licensee MDPI, Basel, Switzerland. This article is an open access article distributed under the terms and conditions of the Creative Commons Attribution (CC BY) license (http://creativecommons.org/licenses/by/4.0/). 